Supporting information

\title{
A Universal Molecular Scaffold for Facile Construction of Multivalent and Multimodal Imaging Probes
}

\author{
Yongkang Gai,${ }^{\dagger}$ Guangya Xiang, ${ }^{\dagger}$ Xiang Ma, ${ }^{\dagger}$ WenQi Hui,${ }^{\ddagger}$ Qin Ouyang, ${ }^{\star}$ Lingyi Sun, ${ }^{\S}$ Jiule Ding, ${ }^{\S}$ \\ Jing Sheng, ${ }^{\S}$ Dexing Zeng ${ }^{\S *}$ \\ ${ }^{\dagger}$ School of Pharmacy, Tongji Medical College, Huazhong University of Science and Technology, Wuhan 430030, \\ China. \\ ${ }^{\ddagger}$ College of Pharmacy, Third Military Medical University, Chongqing 400038, China. \\ ${ }^{\S}$ Department of Radiology, University of Pittsburgh, 100 Technology Drive, Suite 452D, Pittsburgh, PA 15219, \\ USA. E-mail: zengd@upmc.edu
}
I. Synthesis and characterizations (P2-21)
II. DFT computation (P22-29)
III. General radio-labeling procedure and in vitro evaluation (P30-32)
IV. In vivo evaluation (P33-34) 


\section{Reagents and instrumentations}

Aqueous solutions were prepared using ultrapure water (resistivity, $18 \mathrm{M}$ ). Fmoc-PEG 8 carboxylic acid was purchased from Chempep (Wellington, FL). Di-tert-butyl 2,2'-(1,4,7-triazonane-1,4-diyl)diacetate (NO2A(t $\mathrm{Bu})$ ) was prepared according to the literature. ${ }^{[1]} \operatorname{DO} 3 \mathrm{~A}(t \mathrm{Bu})$ was purchased form CheMatech (Dijon, France). BCN-PEG 4 -NHS was purchased from BroadPharm (San Diego, CA). Copper-64 was obtained from Washington University (St. Louis, MO) and University of Wisconsin (Madison, WI). ${ }^{68} \mathrm{Ga}$ (Eckert \& Ziegler Isotope Products, Berlin, Germany) was eluted directly to a Modular-Lab (Eckert \& Ziegler Isotope Products), concentrated on a Strata-X-C column from Phenomenex (Torrance, CA), and the ${ }^{68}$ Ga-eluate was collected by desorbing it with 0.8 $\mathrm{mL}$ of $0.01 \mathrm{M} \mathrm{HCl} / 98 \%$ acetone solution. All other chemicals were purchased from Sigma-Aldrich Chemical Co. (St. Louis, MO) or Fisher Scientific (Pittsburgh, PA), unless otherwise specified. Perkin-Elmer (Packard) Cobra II Gamma counter and Perkin Elmer 2470 WIZARD Automatic Gamma Counter (Waltham, MA) were used to measure gamma radiation. ${ }^{1} \mathrm{H}$ NMR and ${ }^{13} \mathrm{C}$ NMR spectra were recorded on Bruker DRX $400 \mathrm{MHz}$ or $500 \mathrm{MHz}$ spectrometers (Billerica, MA), and ESI-MS were measured on a Waters LCT-Premier XE LC-MS station (Milford, MA). Luna C-18 HPLC columns were from Phenomenex (Torrance, CA, USA). Luna C-18 150*4.6 mm column was used for analysis and purification of small amounts of compounds (less then $1 \mathrm{mg}$ ). Luna C-18 $250 * 10 \mathrm{~mm}$ column was used for purification of large amounts of compounds $(1 \mathrm{mg} \sim 10 \mathrm{mg})$. HPLC were performed on a Waters 1525 Binary HPLC pump (Milford, MA) with a Waters 2489 UV/visible detector and a model 106 Bioscan radioactivity detector for the purification of peptide conjugates and analysis of their ${ }^{64} \mathrm{Cu}$ labeled conjugates using two elution buffers ( $0.1 \mathrm{v} \%$ TFA in de-ionized water as elution buffer $\mathbf{A}$ and $0.1 \mathrm{v} \%$ TFA in acetonitrile as elution buffer B). PET/CT data were acquired using an Inveon Preclinical Imaging Station (Siemens Medical Solutions).

\section{Synthesis and characterization}

\subsection{Synthesis of $\mathrm{N}_{3}-\mathrm{NO}^{t} \mathrm{~B}_{2}$ and $\mathrm{N}_{3}-\mathrm{DO}^{t} \mathrm{~B}_{3}$}

\subsubsection{Synthesis of $\mathrm{N}_{3}-\mathrm{NO}^{t} \mathrm{~B}_{2}$}

\section{4-amino-2-hydroxybutanoate (2)}

$\mathrm{MeCOCl}(15 \mathrm{Ml})$ was dropwise added to anhydrous methanol $(100 \mathrm{Ml})$ at $0^{\circ} \mathrm{C}$. The resulting mixture was stirred at room temperature for $1 \mathrm{~h}$. Then, starting material $1(10 \mathrm{~g}, 84 \mathrm{mmol})$ was added and the mixture was stirred for 2 $\mathrm{h}$ at room temperature. Solvent was removed under reduced pressure, and the residue was treated with ether $(50 \mathrm{Ml})$ to obtain $2(12.67 \mathrm{~g}, 88.5 \%)$ as a white solid after filtration and drying. No further purification is needed suggested by TLC and NMR. ${ }^{1} \mathrm{H}$ NMR (400 MHz, $\left.\mathrm{D}_{2} \mathrm{O}\right) \delta 4.53-4.44(\mathrm{~m}, 1 \mathrm{H},-\mathrm{CH}(\mathrm{COOH})-), 3.82\left(\mathrm{~s}, 3 \mathrm{H},-\mathrm{CH}_{3}\right), 3.27-3.11$ $\left(\mathrm{m}, 2 \mathrm{H},-\mathrm{CH}_{2} \mathrm{~N}_{3}\right), 2.31-2.19\left(\mathrm{~m}, 1 \mathrm{H},-\mathrm{CH}_{2} \mathrm{CH}_{2} \mathrm{~N}_{3}\right), 2.13-1.98\left(\mathrm{~m}, 1 \mathrm{H},-\mathrm{CH}_{2} \mathrm{CH}_{2} \mathrm{~N}_{3}\right) .{ }^{13} \mathrm{C}$ NMR $\left(101 \mathrm{MHz}, \mathrm{D}_{2} \mathrm{O}\right)$ $\delta 175.16,68.50,52.89,36.66,30.42$. ESI-MS: observed, $m / z(\mathrm{M}+\mathrm{H})^{+}=133.92$, calculated, $(\mathrm{M}+\mathrm{H})^{+}=134.08$ 
Imidazole-1-sulfonyl azide hydrochloride ${ }^{[2]}(2.5 \mathrm{~g}, 12 \mathrm{mmol})$ was added to the slurry of $2(1.7 \mathrm{~g}, 5 \mathrm{mmol}), \mathrm{K}_{2} \mathrm{CO}_{3}$ $(3.2 \mathrm{~g}, 23 \mathrm{mmol})$ and $\mathrm{CuSO}_{4} .5 \mathrm{H}_{2} \mathrm{O}(30 \mathrm{mg}, 100 \mu \mathrm{mol})$ in $\mathrm{MeOH}(30 \mathrm{Ml})$ and the mixture was stirred overnight. The mixture was concentrated, diluted with $\mathrm{H}_{2} \mathrm{O}(100 \mathrm{Ml})$, acidified with conc. $\mathrm{HCl}$ and extracted with EtOAc (50 X $3 \mathrm{Ml})$. The combined organic layers were dried $\left(\mathrm{MgSO}_{4}\right)$, filtered and concentrated to obtain crude 3 (1.22 $\mathrm{g}$, $76.6 \%)$ as a colorless liquid. The crude was used in the next step without further purification. For NMR spectra, a little crude was purified by silica gel chromatography (DCM/MeOH, 10:1) to give pure 3 as a colorless liquid, isolation yield $62.0 \% .{ }^{1} \mathrm{H}$ NMR $\left(400 \mathrm{MHz}, \mathrm{CDCl}_{3}\right) \delta 4.31(\mathrm{dd}, J=7.6,4.0 \mathrm{~Hz}, 1 \mathrm{H},-\mathrm{CH}(\mathrm{COOH})-), 3.83(\mathrm{~s}, 3 \mathrm{H}$, $\left.-\mathrm{CH}_{3}\right), 3.59-3.43\left(\mathrm{~m}, 2 \mathrm{H},-\mathrm{CH}_{2} \mathrm{~N}_{3}\right), 2.93(\mathrm{brs}, 1 \mathrm{H},-\mathrm{OH}), 2.15-2.04\left(\mathrm{~m}, 1 \mathrm{H},-\mathrm{CH}_{2} \mathrm{CH}_{2} \mathrm{~N}_{3}\right), 1.99-1.86(\mathrm{~m}, 1 \mathrm{H}$, $\left.-\mathrm{CH}_{2} \mathrm{CH}_{2} \mathrm{~N}_{3}\right) .{ }^{13} \mathrm{C} \mathrm{NMR}\left(101 \mathrm{MHz}, \mathrm{CDCl}_{3}\right) \delta 175.06,67.60,52.81,47.18,33.16$.

\section{methyl 4-azido-2-(tosyloxy)butanoate (4)}

$\mathrm{TsCl}(2.7 \mathrm{~g}, 14 \mathrm{mmol})$ was added to a solution of 3 (1.5 g, $9.4 \mathrm{mmol})$ and TEA (3 g, $30 \mathrm{mmol})$ in DCM (50 Ml) and the mixture was stirred at room temperature overnight. The mixture was then washed by water ( $30 \mathrm{X} 2 \mathrm{Ml})$, dried over $\mathrm{MgSO}_{4}$ and filtered. Concentration of the filtrate and flash chromatography (EtOAc/Hexane, 1:4) gave $4(2.37 \mathrm{~g}, 70.8 \%)$ as a white solid. ${ }^{1} \mathrm{H}$ NMR $\left(400 \mathrm{MHz}, \mathrm{CDCl}_{3}\right) \delta 7.84(\mathrm{~d}, J=8.3 \mathrm{~Hz}, 2 \mathrm{H}, \mathrm{Ar}-\mathrm{H}), 7.38(\mathrm{~d}, J=8.1$ $\mathrm{Hz}, 2 \mathrm{H}, \mathrm{Ar}-\mathrm{H}), 4.97$ (dd, $J=7.6,5.0 \mathrm{~Hz}, 1 \mathrm{H},-\mathrm{CH}(\mathrm{COOH})-), 3.72-3.68\left(\mathrm{~m}, 3 \mathrm{H},-\mathrm{CH}_{3}\right), 3.47-3.39(\mathrm{~m}, 1 \mathrm{H}$, $\left.-\mathrm{CH}_{2} \mathrm{CH}_{2} \mathrm{~N}_{3}\right), 3.37-3.27\left(\mathrm{~m},-\mathrm{CH}_{2} \mathrm{CH}_{2} \mathrm{~N}_{3}\right), 2.47\left(\mathrm{~s}, 3 \mathrm{H}, \mathrm{Ar}-\mathrm{CH}_{3}\right), 2.13-1.98\left(\mathrm{~m}, 2 \mathrm{H},-\mathrm{CH}_{2} \mathrm{~N}_{3}\right) \cdot{ }^{13} \mathrm{C}$ NMR $(101$ $\left.\mathrm{MHz}, \mathrm{CDCl}_{3}\right) \delta 168.68,145.46,132.89,129.88,128.08,74.36,52.77,46.36,31.53,21.69$.

di-tert-butyl 2,2'-(7-(4-azido-1-methoxy-1-oxobutan-2-yl)-1,4,7-triazonane-1,4-diyl)diacetate (5) To a slurry of $\mathrm{NO} 2 \mathrm{~A}(t \mathrm{Bu})^{[1]}(0.8 \mathrm{~g}, 2.24 \mathrm{mmol})$ and $\mathrm{Cs}_{2} \mathrm{CO}_{3}(1.1 \mathrm{~g}, 3.36 \mathrm{mmol})$ in $\mathrm{MeCN}(20 \mathrm{Ml})$ was added 4 $(0.95 \mathrm{~g}, 2.67 \mathrm{mmol})$ and the mixture was heated at $50^{\circ} \mathrm{C}$ for $1 \mathrm{~d}$. After cooling to room temperature, the mixture was filtered and concentrated. The residue was purified by silica gel chromatography (DCM/MeOH, 10:1) to give $5(0.73 \mathrm{~g}, 65.2 \%)$ as a yellowish liquid. ${ }^{1} \mathrm{H}$ NMR $\left(400 \mathrm{MHz}, \mathrm{CDCl}_{3}\right) \delta 3.73-3.60\left(\mathrm{~m}, 3 \mathrm{H},-\mathrm{OCH}_{3}\right), 3.58-3.44(\mathrm{~m}$, $2 \mathrm{H},-\mathrm{CH}_{2} \mathrm{~N}_{3}$ ), 3.39 (s, 1H-NCH-), 3.28 (s, 4H, 2*-CH$\left.{ }_{2} \mathrm{CO}-\right), 3.02-2.58\left(\mathrm{~m}, 12 \mathrm{H}, 6 *-\mathrm{NCH}_{2}-\right), 2.01-1.79(\mathrm{~m}, 2 \mathrm{H}$, $\left.-\mathrm{CH}_{2} \mathrm{CH}_{2} \mathrm{~N}_{3}\right), 1.43\left(\mathrm{~s}, 18 \mathrm{H}, 6{ }^{*}-\mathrm{CH}_{3}\right) .{ }^{13} \mathrm{C} \mathrm{NMR}\left(101 \mathrm{MHz}, \mathrm{CDCl}_{3}\right) \delta 173.51,171.54,80.70,63.83,59.40,56.11$, 55.77, 53.31, 51.23, 48.52, 29.52, 28.21. ESI-MS: observed, $m / z(\mathrm{M}+\mathrm{H})^{+}=499.266$, calculated, $(\mathrm{M}+\mathrm{H})^{+}=499.32$. ESI-HRMS: observed, $m / z(\mathrm{M}+\mathrm{H})^{+}=499.3239$, calculated, $(\mathrm{M}+\mathrm{H})^{+}=499.3239$.

4-azido-2-(4,7-bis(2-(tert-butoxy)-2-oxoethyl)-1,4,7-triazonan-1-yl)butanoic acid $\left(\mathrm{N}_{3}-\mathrm{NO}^{t} \mathrm{~B}_{2}, 6\right)$

To a solution of $5(100 \mathrm{mg}, 0.2 \mathrm{mmol})$ in pyridine $(2 \mathrm{Ml})$ was added LiI $(134 \mathrm{mg}, 1 \mathrm{mmol})$ and the mixture was stirred for $4 \mathrm{~h}$ at room temperature. The mixture was treated with DCM (20 Ml), and washed with saturated citric acid $(10 \mathrm{X} 2 \mathrm{Ml})$ and water $(20 \mathrm{Ml})$. The organic layer was dried over $\mathrm{MgSO}_{4}$, filtered and concentrated to give crude 6. Pure 6 (50 mg, 51.5\%) as a white solid was obtained after purification with silica gel chromatography (DCM/MeOH, 20:3). ${ }^{1} \mathrm{H}$ NMR (400 MHz, $\left.\mathrm{CDCl}_{3}\right) \delta 3.72$ (d, $\left.J=7.1 \mathrm{~Hz}, 1 \mathrm{H},-\mathrm{NCH}(\mathrm{COOH})-\right), 3.70-3.41$ (m, 6H, $\left.2 *-\mathrm{CH}_{2} \mathrm{CO}-\&-\mathrm{CH}_{2} \mathrm{~N}_{3}\right), 3.43-2.75\left(\mathrm{~m}, 12 \mathrm{H}, 6 *-\mathrm{NCH}_{2}-\right), 2.36-2.21\left(\mathrm{~m}, 1 \mathrm{H},-\mathrm{CH}_{2} \mathrm{CH}_{2} \mathrm{~N}_{3}\right), 1.91(\mathrm{dd}, J=12.9$, 
$\left.5.2 \mathrm{~Hz}, 1 \mathrm{H},-\mathrm{CH}_{2} \mathrm{CH}_{2} \mathrm{~N}_{3}\right), 1.46\left(\mathrm{~s}, 18 \mathrm{H}, 6 * \mathrm{CH}_{3}\right) .{ }^{13} \mathrm{C} \mathrm{NMR}\left(101 \mathrm{MHz}, \mathrm{CDCl}_{3}\right) \delta 172.17$ (-COOH), 169.51 $\left(2 *-\mathrm{CO}_{2} \mathrm{C}\left(\mathrm{CH}_{3}\right)_{3}\right), 82.28\left(-\mathrm{CO}_{2} \mathrm{C}\left(\mathrm{CH}_{3}\right)_{3}\right), 63.12(-\mathrm{NCH}(\mathrm{COOH})-), 56.35\left(2 *-\mathrm{NCH}_{2} \mathrm{CO}_{2} \mathrm{C}\left(\mathrm{CH}_{3}\right)_{3}\right), 50.79\left(-\mathrm{N}-\mathrm{CH}_{2}-\right)$, $49.80\left(-\mathrm{N}-\mathrm{CH}_{2}-\right), 49.16\left(-\mathrm{N}_{-} \mathrm{CH}_{2}-\right), 49.04\left(-\mathrm{CH}_{2} \mathrm{~N}_{3}\right), 28.62\left(-\mathrm{CH}_{2} \mathrm{CH}_{2} \mathrm{~N}_{3}\right), 28.12$ (6*-CH3). ESI-MS: observed, $m / z$ $(\mathrm{M}+\mathrm{H})^{+}=485.45$, calculated, $(\mathrm{M}+\mathrm{H})^{+}=485.31$. ESI-HRMS: observed, $\mathrm{m} / \mathrm{z}(\mathrm{M}+\mathrm{H})^{+}=485.3064$, calculated, $(\mathrm{M}+\mathrm{H})^{+}=485.3082$.

\subsubsection{Synthesis of $\mathrm{N}_{3}-\mathrm{DO}^{t} \mathrm{~B}_{3}$}<smiles>CCCCCC(C)C</smiles>

Scheme S1. Synthesis of N3-DOtB 3 . Reagents: a) 4, $\mathrm{CsCO}_{3}, \mathrm{MeCN}$; b) LiI, Pyridine

tri-tert-butyl $\quad$ 2,2',2'-(10-(4-azido-1-methoxy-1-oxobutan-2-yl)-1,4,7,10-tetraazacyclododecane-1,4,7-triyl) triacetate (S2)

To a slurry of $\mathbf{S 1}(\mathrm{DO} 3 \mathrm{~A}(t \mathrm{Bu}))(25.7 \mathrm{mg}, 0.05 \mathrm{mmol})$ and $\mathrm{Cs}_{2} \mathrm{CO}_{3}(25 \mathrm{mg}, 0.075 \mathrm{mmol})$ in $\mathrm{MeCN}(0.5 \mathrm{~mL})$ was added $4(19 \mathrm{mg}, 0.06 \mathrm{mmol})$ and the mixture was shaken at $50^{\circ} \mathrm{C}$ for $1 \mathrm{~d}$. After cooling to room temperature, the mixture was filtered and concentrated. The reaction was monitored by LC-MS. Pure S2 (15 mg, 38.4\%) was obtained after purification with silica gel chromatography (DCM/MeOH, 10:1) ${ }^{1} \mathrm{H} \mathrm{NMR}\left(500 \mathrm{MHz}, \mathrm{CDCl}_{3}\right) \delta 3.70$ $-3.18\left(\mathrm{~m}, 10 \mathrm{H},-\mathrm{CHCO}-\&-\mathrm{NCH}_{2} \mathrm{CO}-\&-\mathrm{OCH}_{3}\right), 3.04-2.07\left(\mathrm{~m}, 16 \mathrm{H}-\mathrm{NCH}_{2}-\right), 1.97-1.81\left(\mathrm{~m}, 2 \mathrm{H},-\mathrm{CH}_{2} \mathrm{~N}\right)$, $1.71-1.63\left(\mathrm{~m}, 2 \mathrm{H},-\mathrm{CH}_{2} \mathrm{CH}_{2} \mathrm{~N}_{3}\right), 1.48-1.45\left(\mathrm{~m}, 27 \mathrm{H}, 9^{*}-\mathrm{CH}_{3}\right) .{ }^{13} \mathrm{C}$ NMR $\left(126 \mathrm{MHz}, \mathrm{CDCl}_{3}\right) \delta 175.86$, $173.27,173.09,172.92,82.27,82.03,81.97,57.44,55.93,55.81,55.59,52.76,52.62,52.45$ (2C), 50.10, 48.89, 48.77, 48.43, 47.42, 45.08, 27.91 (6C), $27.85(3 \mathrm{C}), 24.04$. ESI-MS: observed, $m / z(\mathrm{M}+\mathrm{H})^{+}=$ 656.455, calculated, $(\mathrm{M}+\mathrm{H})^{+}=656.435$. ESI-HRMS: observed, $m / z(\mathrm{M}+\mathrm{H})^{+}=656.4322$, calculated, $(\mathrm{M}+\mathrm{H})^{+}=$ 656.4347 .

\section{4-azido-2-(4,7,10-tris(2-(tert-butoxy)-2-oxoethyl)-1,4,7,10-tetraazacyclododecan-1-yl)butanoic acid (S3)}

To a solution of $\mathbf{S 2}(10 \mathrm{mg}, 0.015 \mathrm{mmol})$ in pyridine $(0.5 \mathrm{~mL})$ was added LiI $(10 \mathrm{mg}, 0.075 \mathrm{mmol})$ and the mixture was shaken for $2 \mathrm{~h}$ at room temperature. The mixture was treated with DCM, and washed with saturated citric acid and water. The organic layer was dried over $\mathrm{MgSO}_{4}$, filtered and concentrated to give crude S3. Silica gel chromatography (DCM/MeOH, 10:1) was applied to obtain $\mathbf{S 3}$ (3 mg, 31.2\%). ${ }^{1} \mathrm{H}$ NMR (500 MHz, $\left.\mathrm{CDCl}_{3}\right) \delta 3.87$ -3.74 (m, 2H, - $\left.\mathrm{CH}_{2} \mathrm{CO}-\right), 3.63-3.53$ (m, 1H, - $\left.\mathrm{NCH}(\mathrm{COOH})-\right), 3.46-3.33$ (m, 4H, $\left.-\mathrm{CH}_{2} \mathrm{CO}-\right), 3.08-1.98$ (m, $\left.18 \mathrm{H},-\mathrm{NCH}_{2}-\&-\mathrm{CH}_{2} \mathrm{~N}\right), 1.67-1.56\left(\mathrm{~m}, 2 \mathrm{H},-\mathrm{CH}_{2} \mathrm{CH}_{2} \mathrm{~N}_{3}\right), 1.51-1.46\left(\mathrm{~m}, 27 \mathrm{H}, 9 *-\mathrm{CH}_{3}\right)$. ESI-MS: observed, $m / z$ $(\mathrm{M}+\mathrm{H})^{+}=642.439$, calculated, $(\mathrm{M}+\mathrm{H})^{+}=642.419$. ESI-HRMS: observed, $m / z(\mathrm{M}-\mathrm{H})^{-}=640.4046$, calculated, $(\mathrm{M}-\mathrm{H})^{-}=640.4034$. 
$1.2{ }^{1} \mathrm{H}-\mathrm{NMR},{ }^{13} \mathrm{C}-\mathrm{NMR}$, and HRMS spectra

${ }^{1} \mathrm{H}-\mathrm{NMR}$ and ${ }^{13} \mathrm{C}$-NMR spectra of compound 2
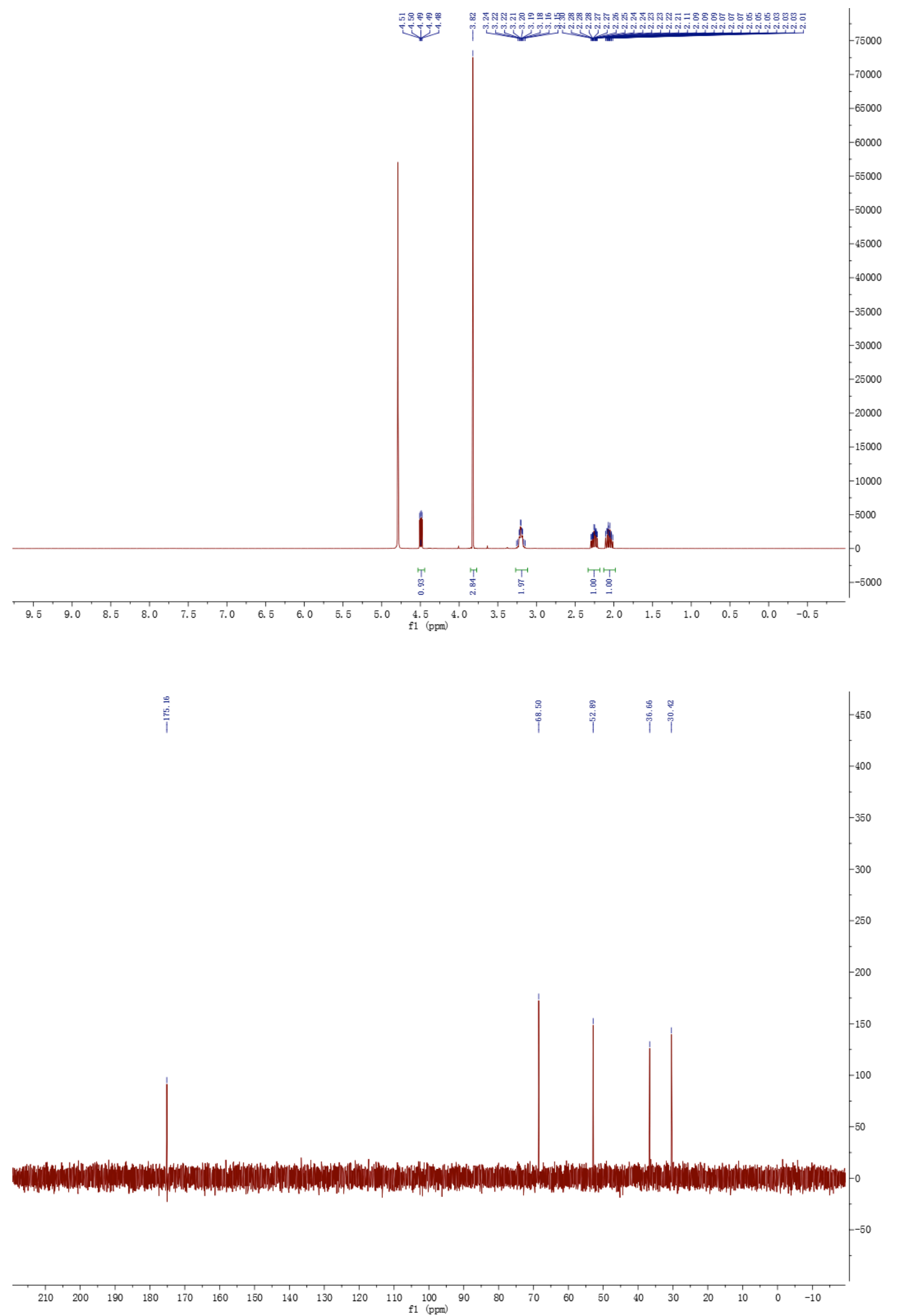
${ }^{1} \mathrm{H}-\mathrm{NMR}$ and ${ }^{13} \mathrm{C}$-NMR spectra of compound 3
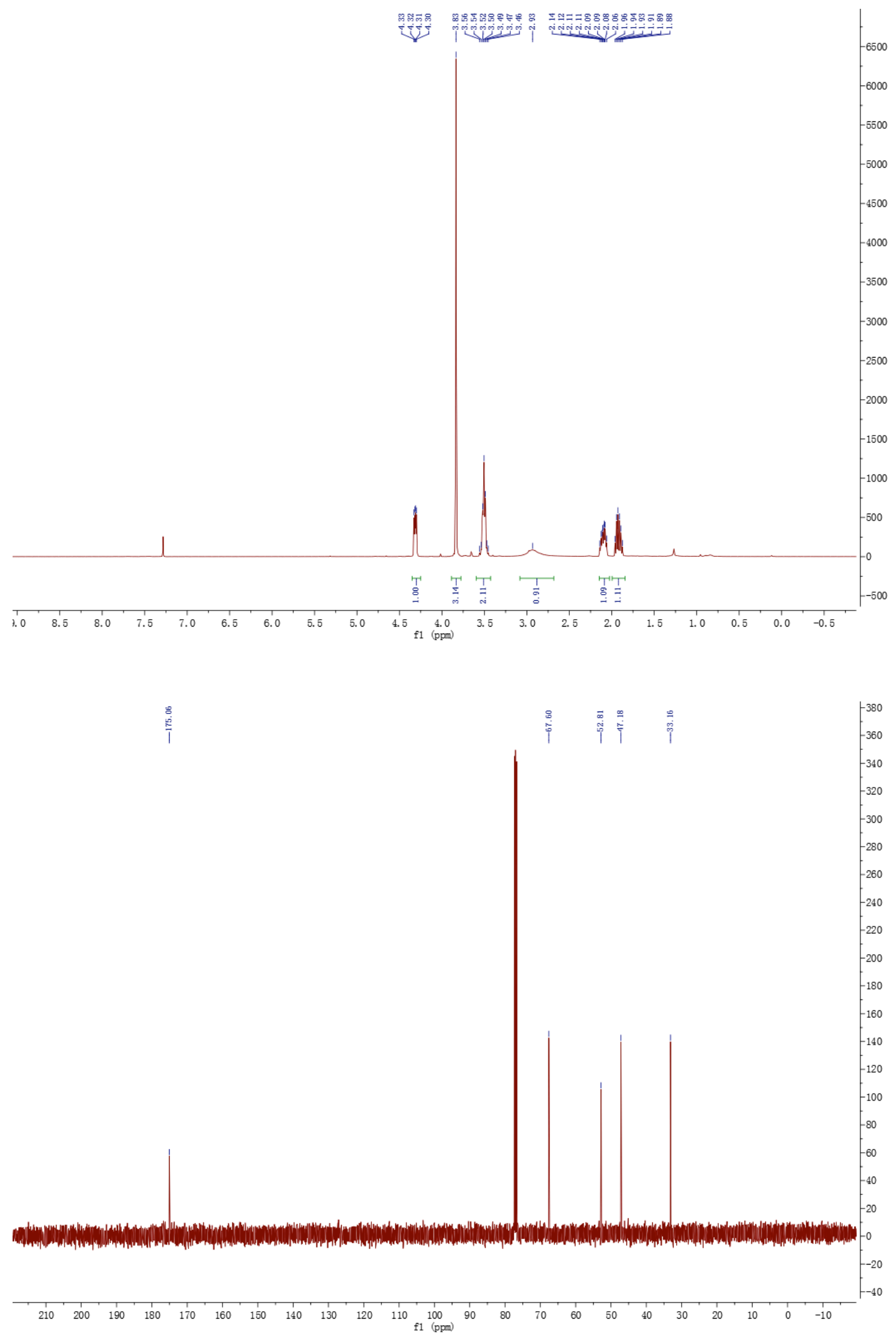
${ }^{1} \mathrm{H}-\mathrm{NMR}$ and ${ }^{13} \mathrm{C}$-NMR spectra of compound 4

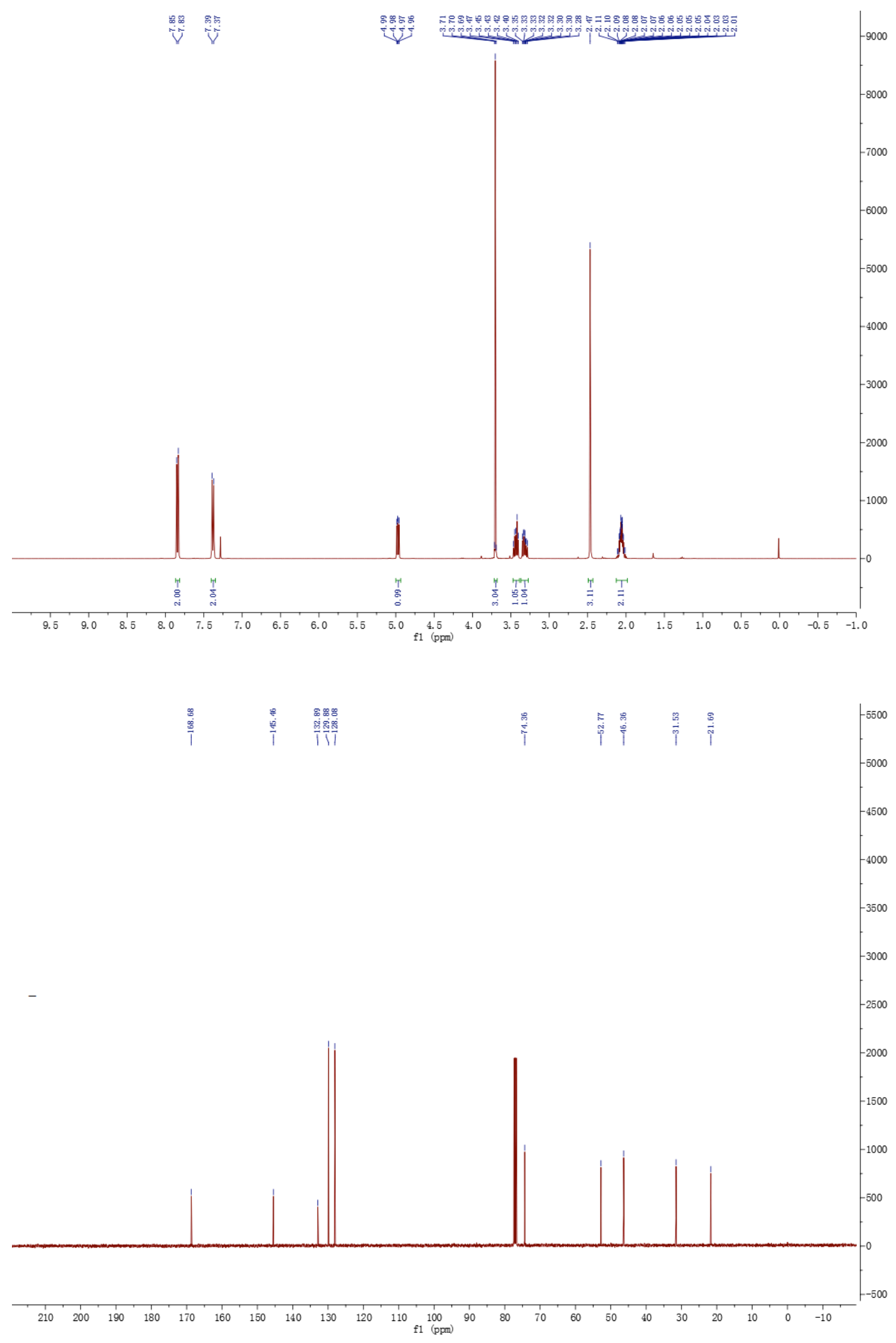


${ }^{1} \mathrm{H}-\mathrm{NMR},{ }^{13} \mathrm{C}-\mathrm{NMR}$ and HRMS spectra of compound 5
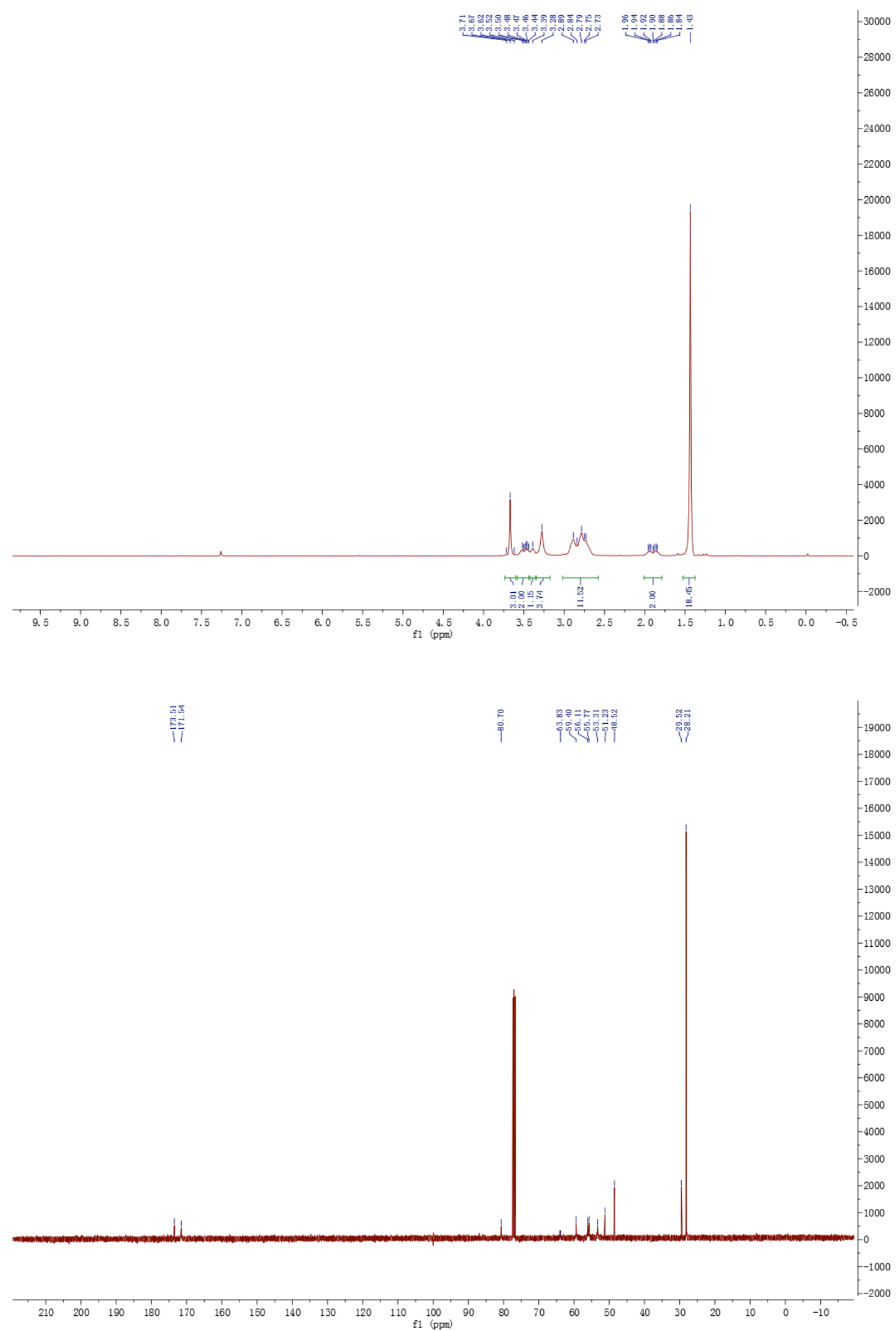


\section{Mass Spectrum SmartFormula Report}

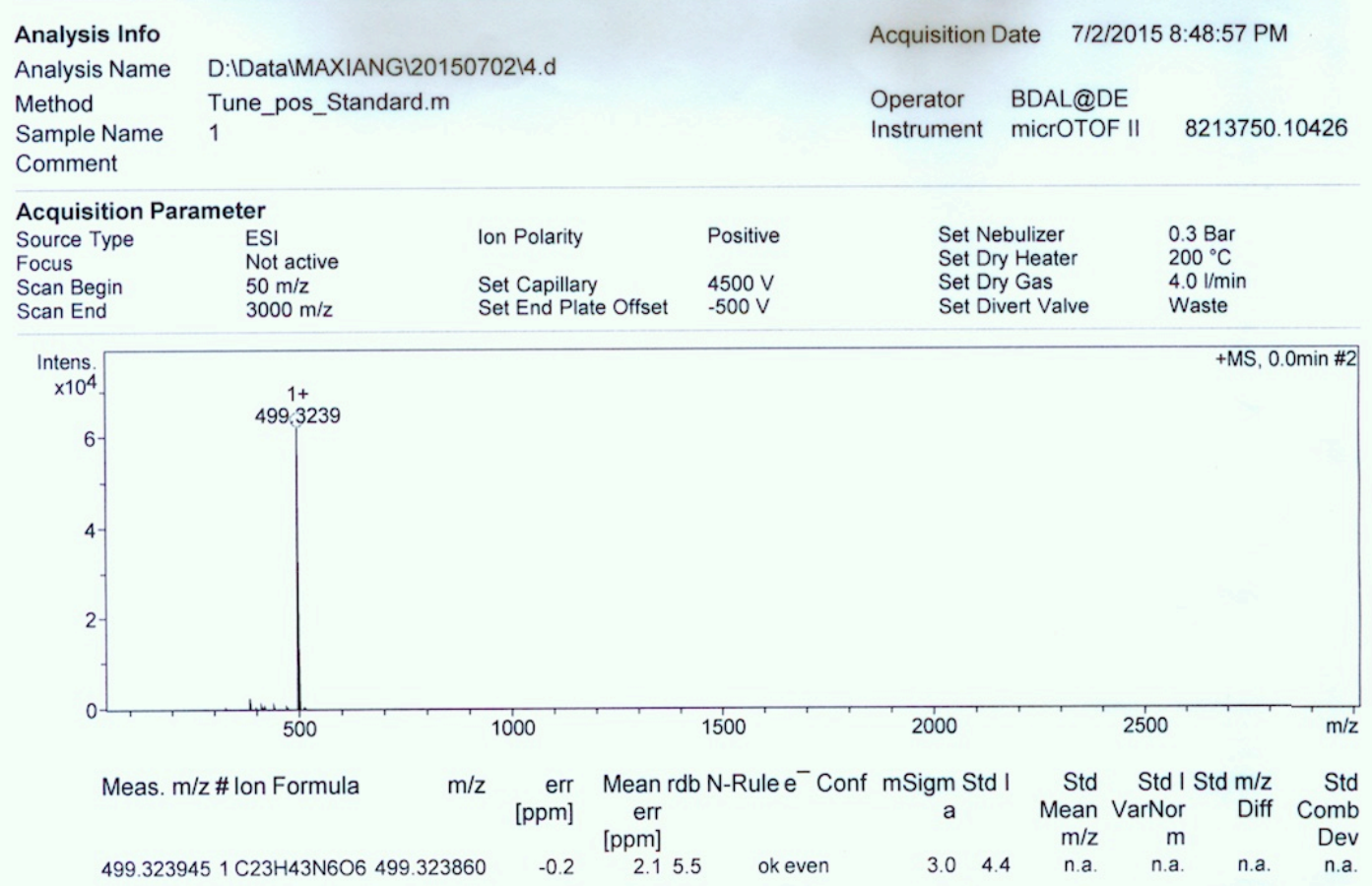


${ }^{1} \mathrm{H}-\mathrm{NMR},{ }^{13} \mathrm{C}-\mathrm{NMR}$ and HRMS spectra of compound 6
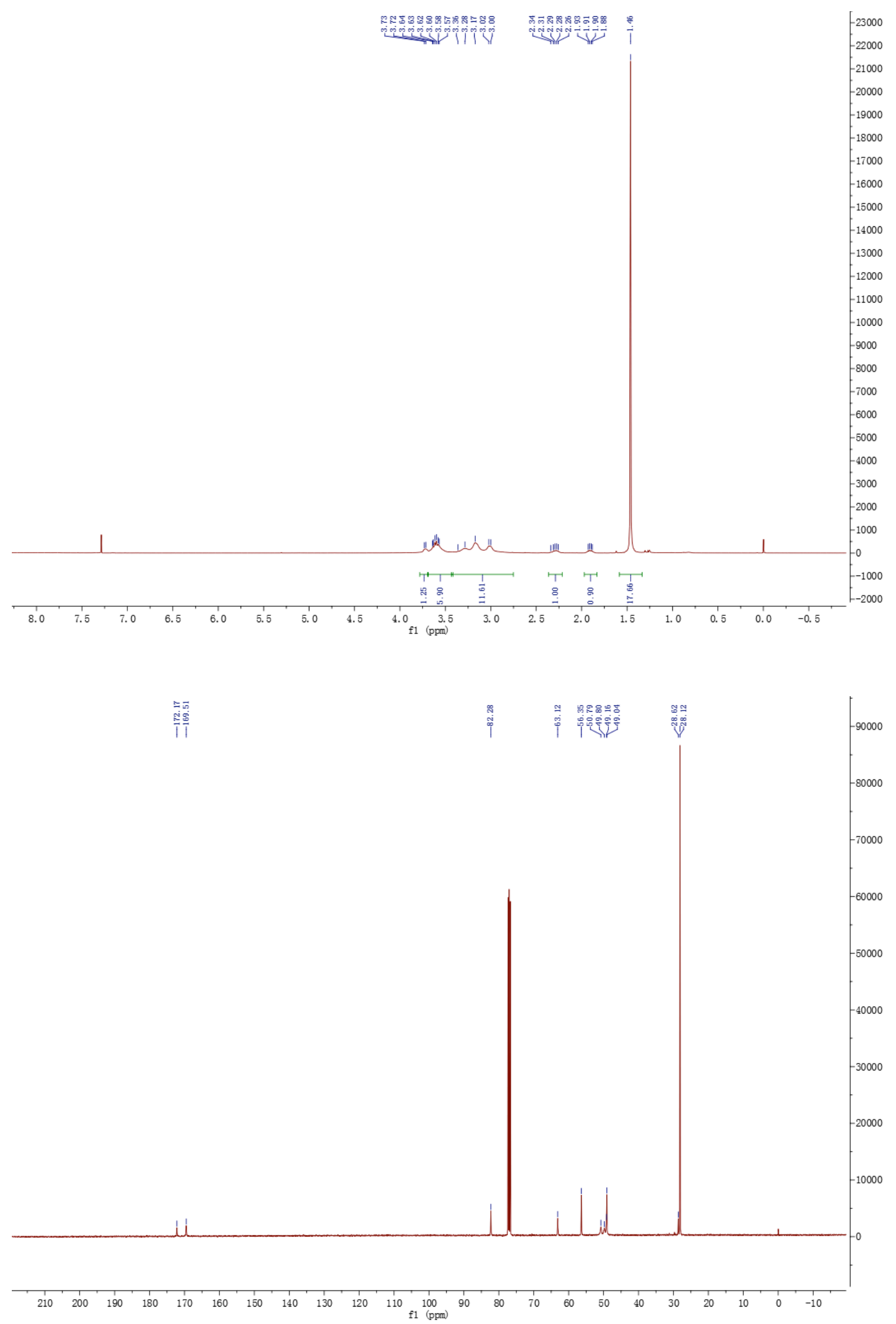


\section{Mass Spectrum SmartFormula Report}

\section{Analysis Info}

Analysis Name

Method

Sample Name

Comment

Acquisition Date 9/23/2015 4:40:29 PM

D:IDatalMAXIANGI20150923IGYK.d

Tune_pos_Standard.m

Operator BDAL@DE

Instrument micrOTOF ॥ $\quad 8213750.10426$

Acquisition Parameter

Source Type ESI

Focus

Not active

$50 \mathrm{~m} / \mathrm{z}$

$3000 \mathrm{~m} / \mathrm{z}$

Ion Polarity

Positive

Set Capillary

Set End Plate Offset $\quad 4500 \mathrm{~V}$

$-500 \mathrm{~V}$ 2356.0003

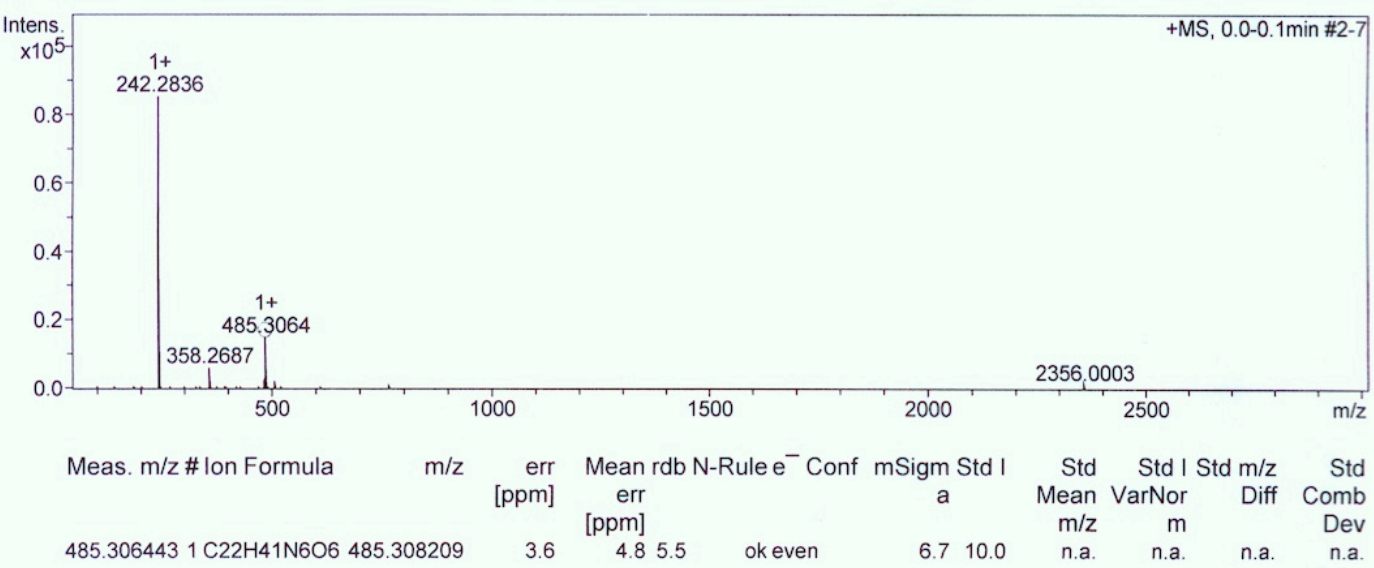


${ }^{1} \mathrm{H}-\mathrm{NMR},{ }^{13} \mathrm{C}-\mathrm{NMR}$ and HRMS spectra of compound S2
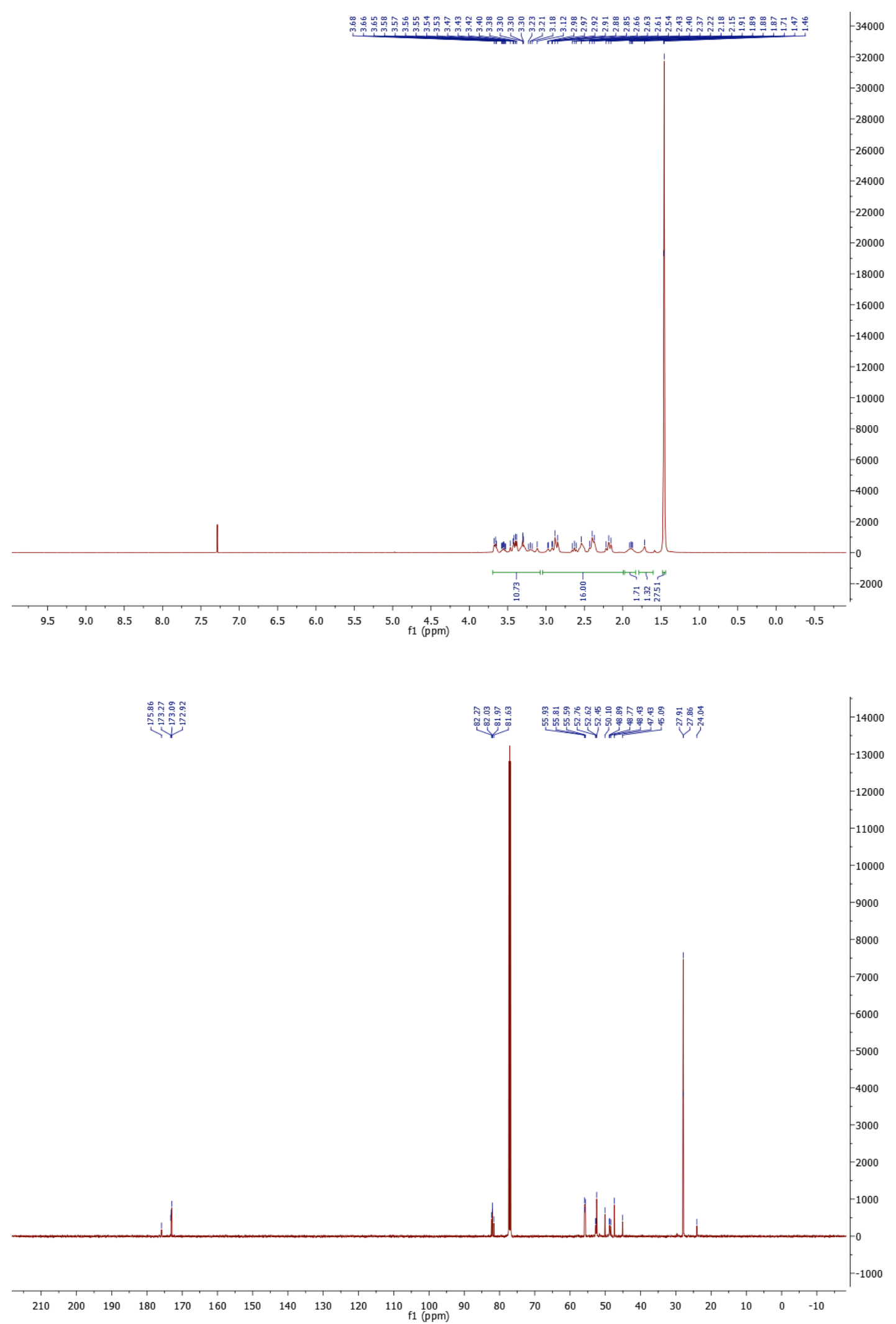
74616ESIP\#22-60 RT: 0.13-0.33 AV: 39

$\mathrm{T}: \mathrm{FTMS}+\mathrm{p}$ ESI Full ms [133.40-2000.00]

$\mathrm{m} / \mathrm{z}=655.95745-656.72676$

\begin{tabular}{|c|c|c|c|c|c}
$\mathrm{m} / \mathrm{z}$ & Intensity & Relative & Theo. Mass & $\begin{array}{c}\text { Delta } \\
(\mathrm{ppm})\end{array}$ & Composition \\
$\mathbf{6 5 6 . 4 3 2 1 8}$ & 1204921600.0 & 100.00 & 656.43414 & -2.98 & $\mathrm{C}_{31} \mathrm{H}_{58} \mathrm{O}_{8} \mathrm{~N}_{7}$
\end{tabular}

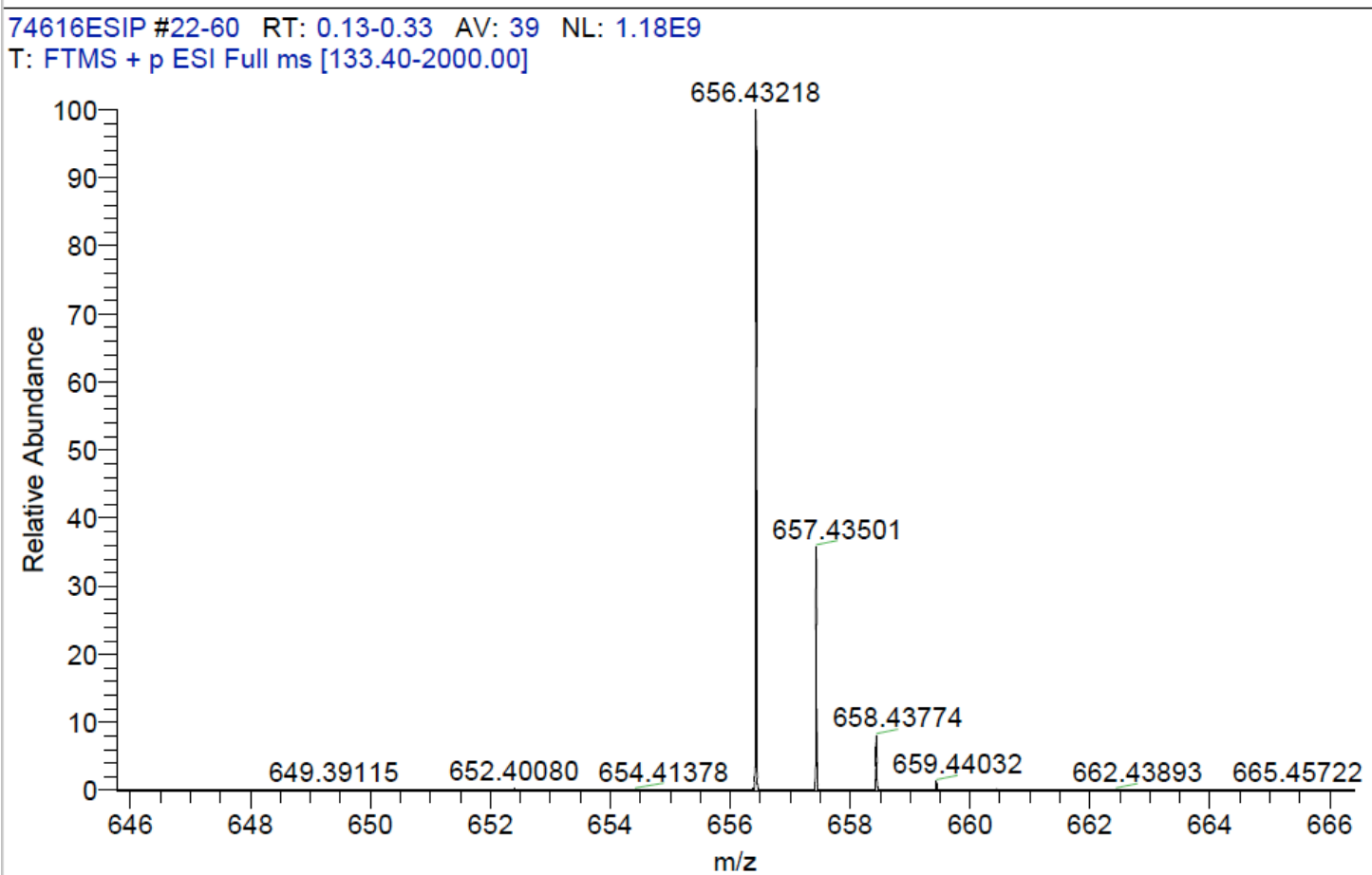


${ }^{1} \mathrm{H}-\mathrm{NMR}$ and HRMS spectra of compound S3
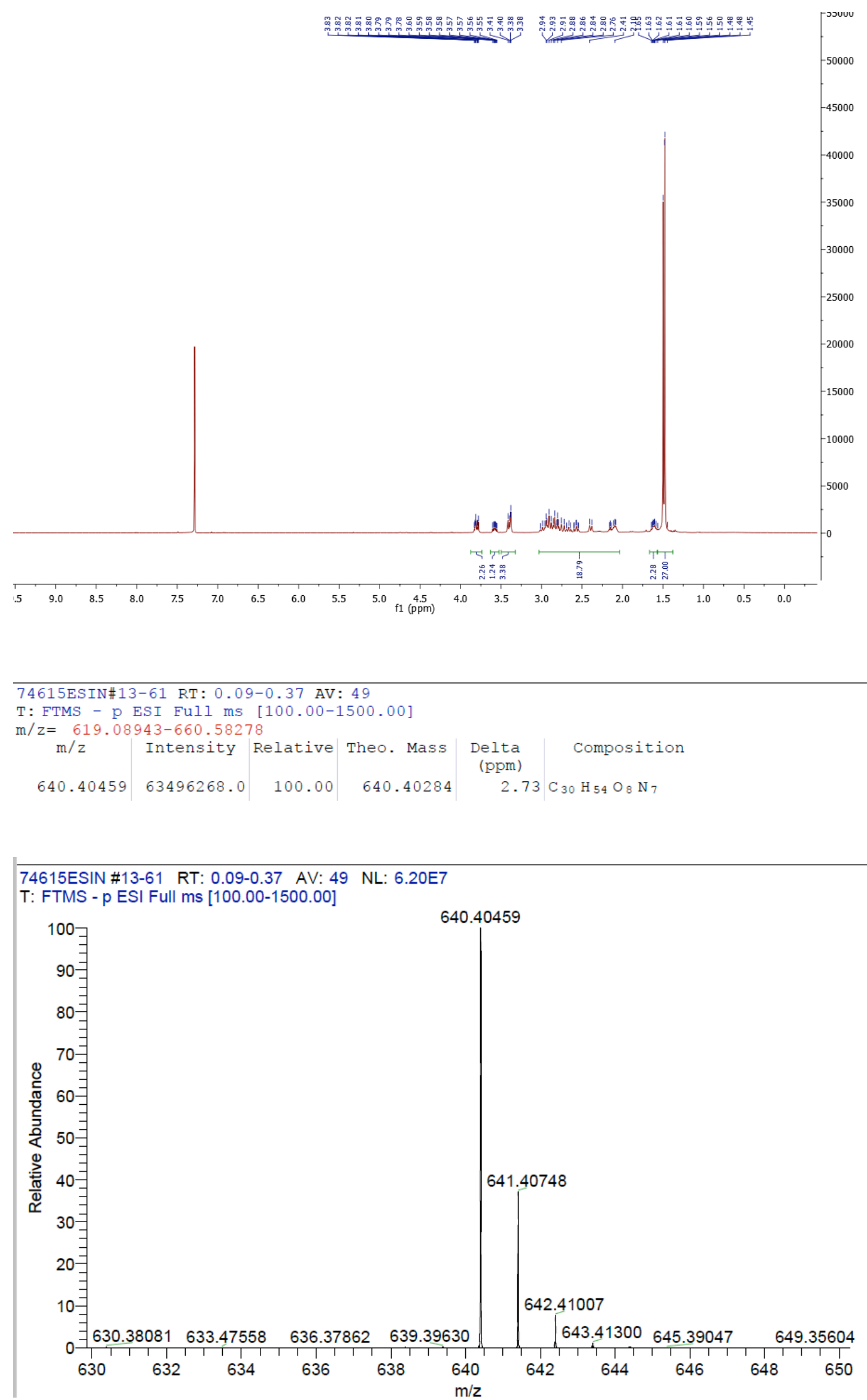
1.3 Synthesis of heterodimers, homodimers, and multimodality probes using scaffold $\mathrm{N}_{3}-\mathrm{NO}^{\text {t }} \mathrm{B}_{2}$ via metal-free click chemistry

\subsubsection{General procedure for preparation of Moiety-A-NOTA-N 3 (7)}

Peptides on resin (Resin-AE105*, Resin-AE105-PEG8-NH2) were prepared using standard SPPS protocol by a peptide synthesizer. Compound 6 (3 eq.) was coupled to the resin by mixing them with HATU (5 eq.) and DIEA (10 eq.) in DMF (1 2 mL) for $2 \mathrm{~h}$ at room temperature. Moiety-A-NOTA-N $\mathrm{N}_{3}$ (7) was then obtained after cleavage from resin support using TFA/ $\mathrm{H}_{2} \mathrm{O} / \mathrm{TIS} /$ phenol (90:5:2.5:2.5) and HPLC purification using two elution buffers ( 0.1 v\% TFA in de-ionized water as elution buffer $\mathbf{A}$ and 0.1 v\% TFA in acetonitrile as elution buffer $\mathbf{B})$.

*AE105 sequence: Asp-Cha-Phe-(D)Ser-(D)Arg-Tyr-Leu-Trp-Ser-amide, targeting urokinase receptor (uPAR)

\section{AE105-NOTA-N ${ }_{3}$ (7a)}

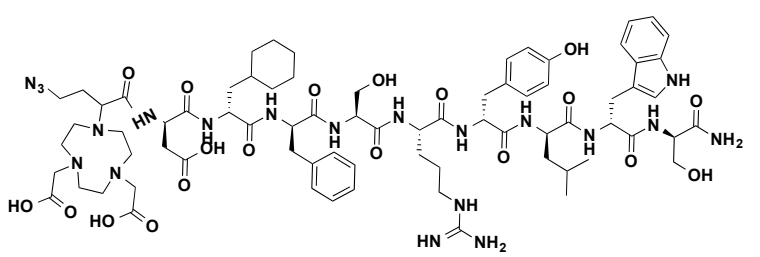

HPLC conditions: Luna C-18 250*10 mm column, $4 \mathrm{ml} / \mathrm{min}, 0 \sim 5 \mathrm{~min} 20 \% \mathrm{~B}, 5 \sim 25 \mathrm{~min}$ from $20 \% \mathrm{~B}$ to $60 \% \mathrm{~B}$. Retention time $19.50 \mathrm{~min}$. Luna C-18 250*10 mm column, $1.5 \mathrm{ml} / \mathrm{min}, 0 \sim 3 \mathrm{~min} 20 \% \mathrm{~B}, 3 \sim 28 \mathrm{~min}$ from $20 \%$ B to $60 \%$ B. Retention time $22.50 \mathrm{~min}$. Yield, 50 65\%. ESI-MS: observed, $\mathrm{m} / z(\mathrm{M}+\mathrm{H})^{+}=1579.161$, calculated, $(\mathrm{M}+\mathrm{H})^{+}=1579.798$

\section{AE105-PEG8-NOTA-N $3(7 b)$}

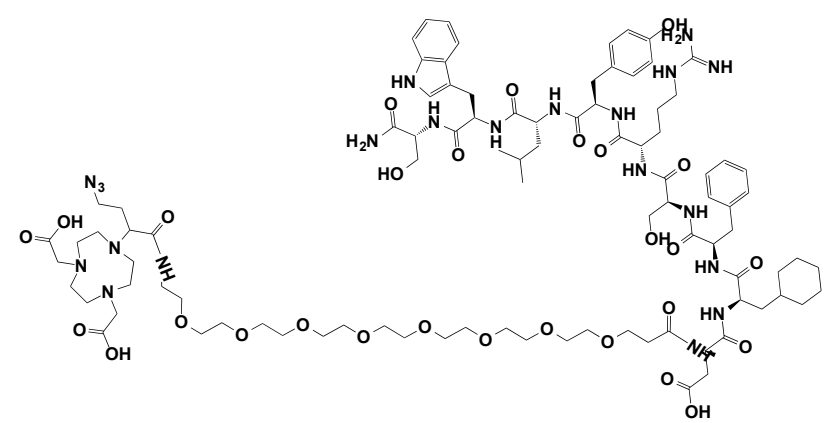

HPLC conditions: Luna C-18 250*10 mm column, $4 \mathrm{ml} / \mathrm{min}, 0 \sim 3 \mathrm{~min} 30 \% \mathrm{~B}, 3 \sim 33 \mathrm{~min}$ from $30 \% \mathrm{~B}$ to $60 \% \mathrm{~B}$. Retention time $18.95 \mathrm{~min}$. Luna C-18 150*4.6 mm column, $1.5 \mathrm{ml} / \mathrm{min}, 0 \sim 3 \mathrm{~min} 20 \% \mathrm{~B}, 3 \sim 28 \mathrm{~min}$ from $20 \%$ B to $60 \%$ B. Retention time $21.69 \mathrm{~min}$. Yield, 40 60\%. ESI-MS: observed, $m / z(\mathrm{M}+2 \mathrm{H})^{2+}=1001.398$, calculated, $(\mathrm{M}+2 \mathrm{H})^{2+}=1002.53$. 


\subsubsection{General procedure for preparation of BCN functionalized Moiety-B}

For the peptides that only contain one primary amine, BCN-PEG 4 -NHS (1.1 eq.) was directly mixed with the peptide and DIEA (3 5 eq.) in DMF $(0.1 \sim 0.3 \mathrm{~mL})$. The resulting mixture was reacted at room temperature for $4 \mathrm{~h}$. Moiety-B-BCN was then obtained after purification. For the peptides that have more than one primary amine, peptides on resin were used instead of free peptides. Briefly, peptide on resin was mixed with $\mathrm{BCN}-\mathrm{PEG}_{4}-\mathrm{NHS}$ (3 eq.) and DIEA (5 eq.) in DMF $(0.5 \sim 1 \mathrm{~mL})$, and the mixture was reacted at room temperature for $4 \mathrm{~h}$. Pure Moiety-B-BCN was then obtained after HPLC purification using two elution buffers $(0.1 \mathrm{v} \%$ TFA in de-ionized water as elution buffer $\mathbf{A}$ and 0.1 v\% TFA in acetonitrile as elution buffer $\mathbf{B}$ ).

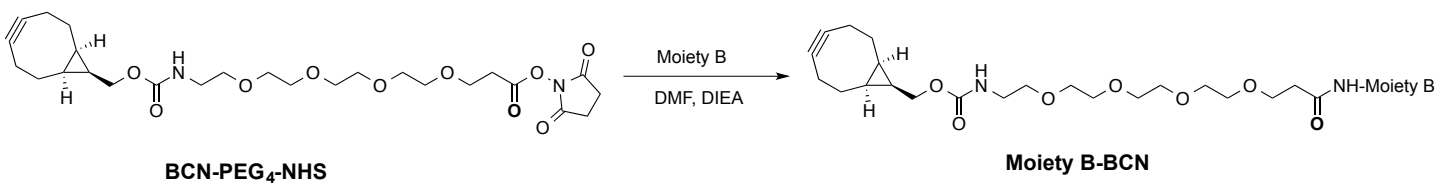

\section{RGDyK-PEG4-BCN*}

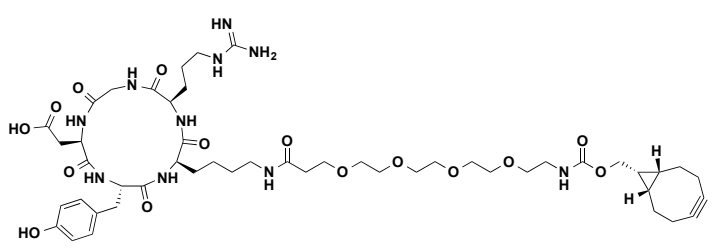

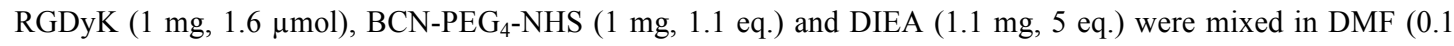
$\mathrm{mL}$ ). After reacting at room temperature for $4 \mathrm{~h}$, the reaction mixture was diluted with $0.9 \mathrm{~mL}$ water and pure RGDyK-PEG4-BCN was obtained after HPLC purification (1.2 mg, 71.9\%). HPLC conditions: Luna C-18 $150 * 4.6 \mathrm{~mm}$ column, $1.5 \mathrm{ml} / \mathrm{min}, 0 \sim 3 \mathrm{~min} 10 \% \mathrm{~B}, 3 \sim 33 \mathrm{~min}$ from $10 \% \mathrm{~B}$ to $40 \% \mathrm{~B}$. Retention time $26.7 \mathrm{~min}$. ESI-MS: observed, $m / z(\mathrm{M}+\mathrm{H})^{+}=1043.432$, calculated, $(\mathrm{M}+\mathrm{H})^{+}=1043.537$

*RGDyK (c(RGDyK)) sequence: cyclo(Gly - Arg - Lys -Tyr - Asp), targeting $\alpha_{v} \beta_{3}$ integrin

\section{AE105-PEG4-BCN}

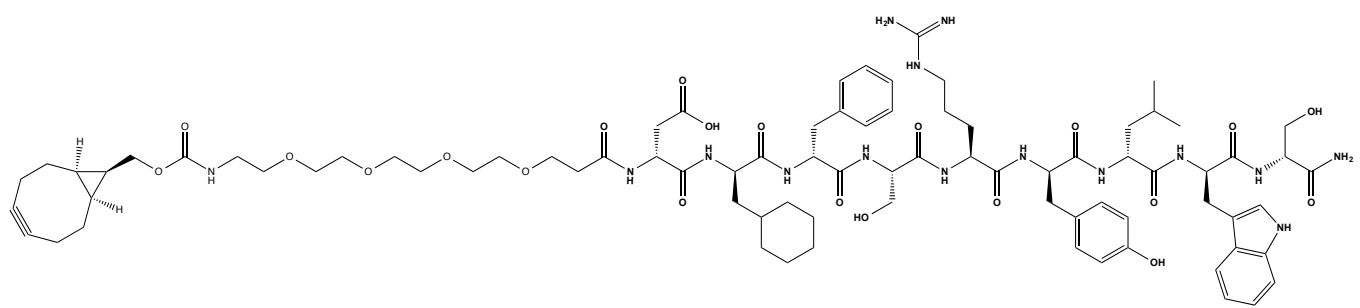

The synthesis of AE105-PEG $-\mathrm{BCN}$ was similar to that of $\mathrm{RGDyK}-\mathrm{PEG}_{4}-\mathrm{BCN}$, except peptide AE105 was used. HPLC conditions: Luna C-18 150*4.6 mm column, $1.5 \mathrm{ml} / \mathrm{min}, 0 \sim 3 \mathrm{~min} 20 \% \mathrm{~B}, 3 \sim 33 \mathrm{~min}$ from $20 \% \mathrm{~B}$ to $50 \% \mathrm{~B}$. Retention time 22.79 min. Yield, 67\%. ESI-MS: observed, $m / z(\mathrm{M}+\mathrm{H})^{+}=1649.834$, calculated, $(\mathrm{M}+\mathrm{H})^{+}=1648.858$ 
DAPTA-PEG 4 -BCN*

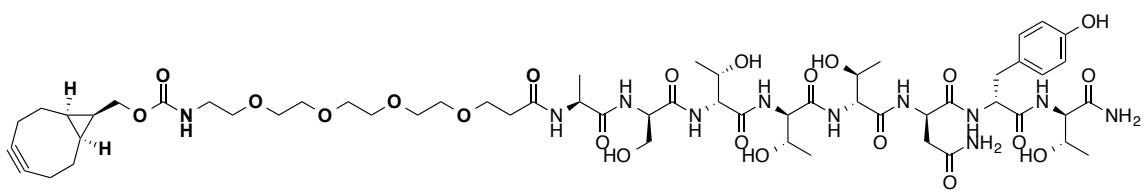

The synthesis of DAPTA-PEG $-\mathrm{BCN}$ was similar to that of $\mathrm{RGDyK}-\mathrm{PEG}_{4}-\mathrm{BCN}$, except peptide DAPTA was used. HPLC conditions: Luna C-18 150*4.6 mm column, $1.5 \mathrm{ml} / \mathrm{min}, 0 \sim 3 \mathrm{~min} 10 \% \mathrm{~B}, 3 \sim 33 \mathrm{~min}$ from $10 \% \mathrm{~B}$ to $50 \% \mathrm{~B}$. Retention time $22.49 \mathrm{~min}$. Yield, 70\%. MALDI-MS: observed, $\mathrm{m} / \mathrm{z}(\mathrm{M}+\mathrm{Na})^{+}=1304.0$, calculated, $(\mathrm{M}+\mathrm{Na})^{+}=1302.6$

*DAPTA sequence: D-Ala-Ser-Thr-Thr-Thr-Asn-Tyr-Thr-amide, targeting chemokine receptor type 5 (CCR5)

\section{LLP2A-PEG -BCN $^{*}$}

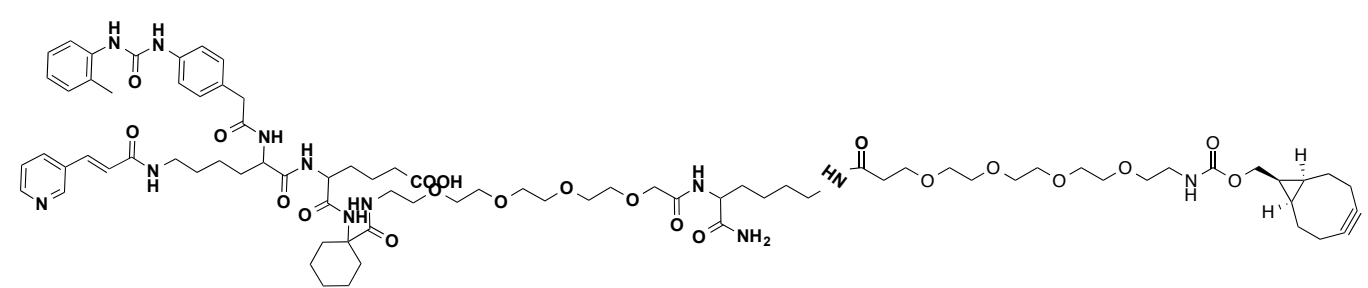

The synthesis of LLP2A-PEG 8 -BCN was similar to that of RGDyK-PEG 4 -BCN, except peptide LLP2A-PEG 4 was used. HPLC conditions: Luna C-18 150*4.6 mm column, $1.5 \mathrm{ml} / \mathrm{min}, 0 \sim 3 \mathrm{~min} 10 \% \mathrm{~B}, 3 \sim 33 \mathrm{~min}$ from $10 \% \mathrm{~B}$ to $40 \%$ B. Retention time $21.4 \mathrm{~min}$. Yield, 89\%. MALDI-MS: observed, $\mathrm{m} / \mathrm{z}(\mathrm{M}+\mathrm{Na})^{+}=1620.4$, calculated, $(\mathrm{M}+\mathrm{Na})^{+}=1617.8$

*LLP2A-PEG4, targeting $\alpha_{4} \beta_{1}$ integrin (Very late antigen 4, VLA-4).

\section{Cy5-PEG 4 -BCN*}

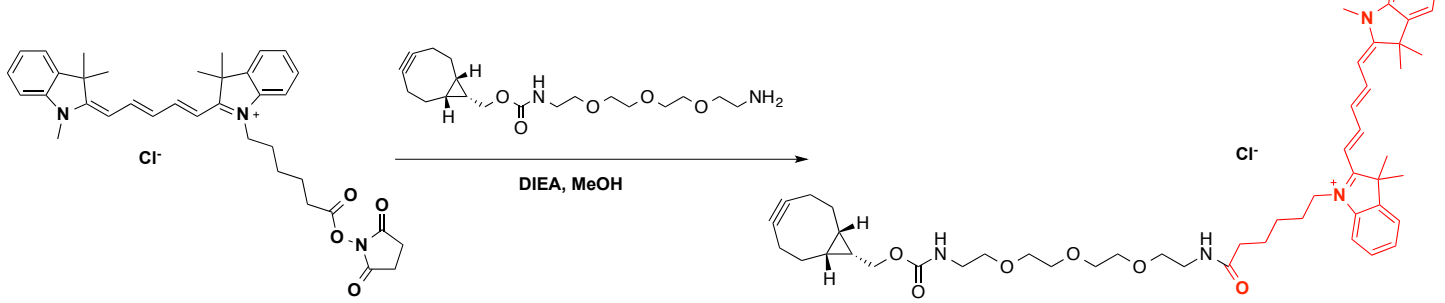

To a solution of $\mathrm{BCN}_{-} \mathrm{PEG}_{4}-\mathrm{NH}_{2}(1 \mathrm{mg})$ in $\mathrm{MeOH}(1 \mathrm{~mL})$ was added Cy5-NHS ester $(1.83 \mathrm{mg}, 1.1 \mathrm{eq}$. $)$ and DIEA (1.1 mg, 5 eq.), and the resulting mixture was reacted at room temperature for 4 hrs. Pure Cy5-PEG $-\mathrm{BCN}_{4}(1.3 \mathrm{mg}$, 60\%) was obtained after HPLC purification. HPLC conditions: Luna C-18 250*10 mm column, $4 \mathrm{ml} / \mathrm{min}, 0 \sim 3 \mathrm{~min}$ $20 \% \mathrm{~B}, 3 \sim 33 \mathrm{~min}$ from $20 \% \mathrm{~B}$ to $50 \% \mathrm{~B}$. Retention time 26.9 min. ESI-MS: observed, $\mathrm{m} / \mathrm{z}(\mathrm{M}+\mathrm{H})^{+}=832.630$, calculated, $(\mathrm{M}+\mathrm{H})^{+}=834.524$ 
*Cy5 (Cyanine5), a fluorescent dye.

\subsubsection{General procedure for conjugating Moiety-A-NOTA-N ${ }_{3}$ to Moiety-B-BCN using SPPAC}

Moiety-A-NOTA-N ${ }_{3}(1$ eq., $0.01 \sim 1 \mu \mathrm{mol})$ and Moiety-B-BCN (1 eq.) were mixed in $50 \% \mathrm{MeCN} / \mathrm{H}_{2} \mathrm{O}(0.5 \sim 1 \mathrm{~mL})$, and reacted overnight at room temperature. The conjugate was then obtained after lyophilization. Usually the reactions were accomplished in quantitative yield (one of the moieties was fully reacted.) and over $95 \%$ purity could be achieved, thus no HPLC purification was needed in this step.

\section{AE105-PEG 4 -click-NOTA-AE105 (8a)}

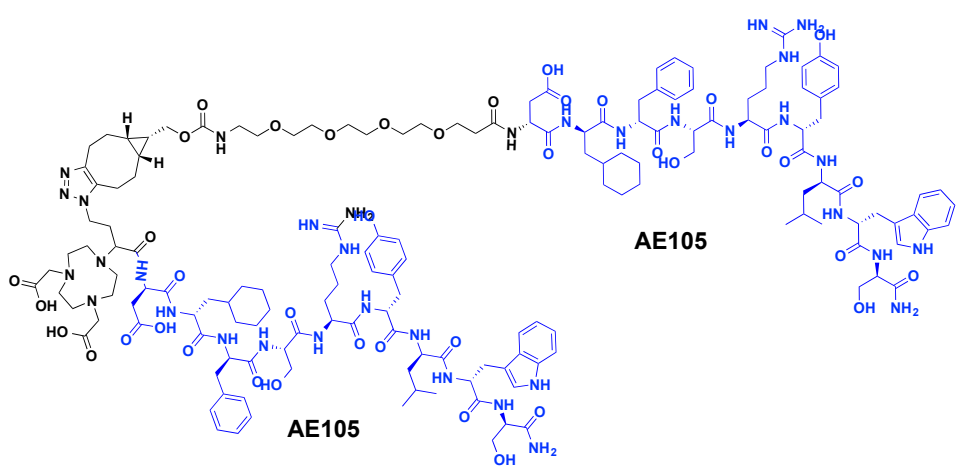

HPLC conditions: Luna C-18 150*4.6 mm column, $1.5 \mathrm{ml} / \mathrm{min}, 0 \sim 3 \mathrm{~min} 20 \% \mathrm{~B}, 3 \sim 28 \mathrm{~min}$ from $20 \% \mathrm{~B}$ to $50 \% \mathrm{~B}$. Retention time 25.6 min. Yield, $>95 \%$; purity, $>95 \%$. ESI-MS: observed, $m / z(M+2 H)^{2+}=1613.381$, calculated, $(\mathrm{M}+2 \mathrm{H})^{2+}=1614.324$

\section{Cy5-PEG 4 -click-NOTA-AE105 (8b)}

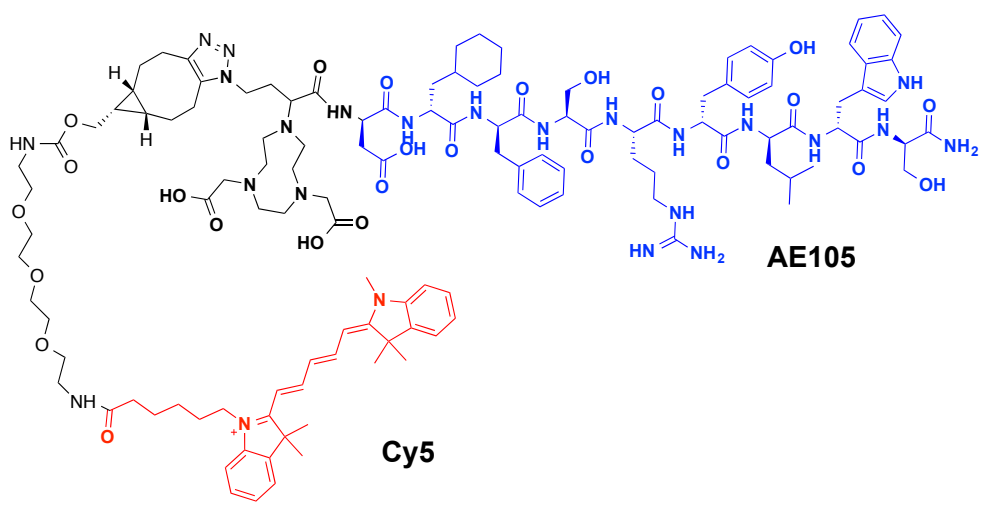

HPLC conditions: Luna C-18 150*4.6 mm column, $1.5 \mathrm{ml} / \mathrm{min}, 0 \sim 3 \mathrm{~min} 30 \% \mathrm{~B}, 3 \sim 23 \mathrm{~min}$ from $30 \% \mathrm{~B}$ to $50 \% \mathrm{~B}$. Retention time 16.5 min. Yield, $>95 \%$; purity, $>95 \%$. ESI-MS: observed, $m / z(M+2 H)^{2+}=1205.879$, calculated, $(\mathrm{M}+2 \mathrm{H})^{2+}=1207.1655$ 


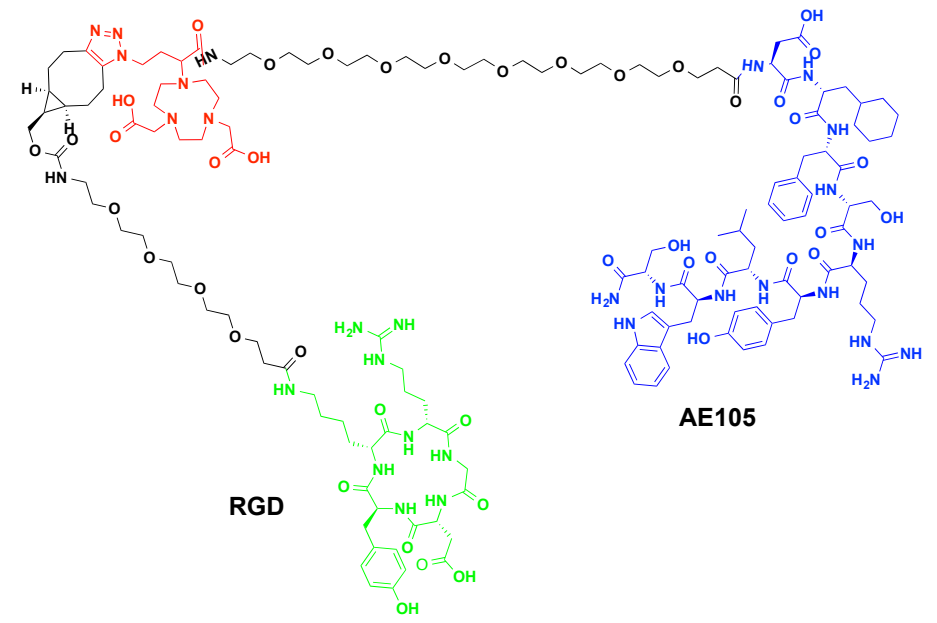

HPLC conditions: Luna C-18 150*4.6 mm column, $1.5 \mathrm{ml} / \mathrm{min}, 0 \sim 3 \mathrm{~min} 20 \% \mathrm{~B}, 3 \sim 33 \mathrm{~min}$ from $20 \% \mathrm{~B}$ to $50 \% \mathrm{~B}$. Retention time: $20.03 \mathrm{~min}$. Yield, $>95 \%$; purity, $>95 \%$. ESI-MS: observed, $m / z(\mathrm{M}+2 \mathrm{H})^{2+}=1522.109$, calculated, $(\mathrm{M}+2 \mathrm{H})^{2+}=1523.79$

\section{DAPTA-PEG 4 -click-NOTA-AE105 (8d)}

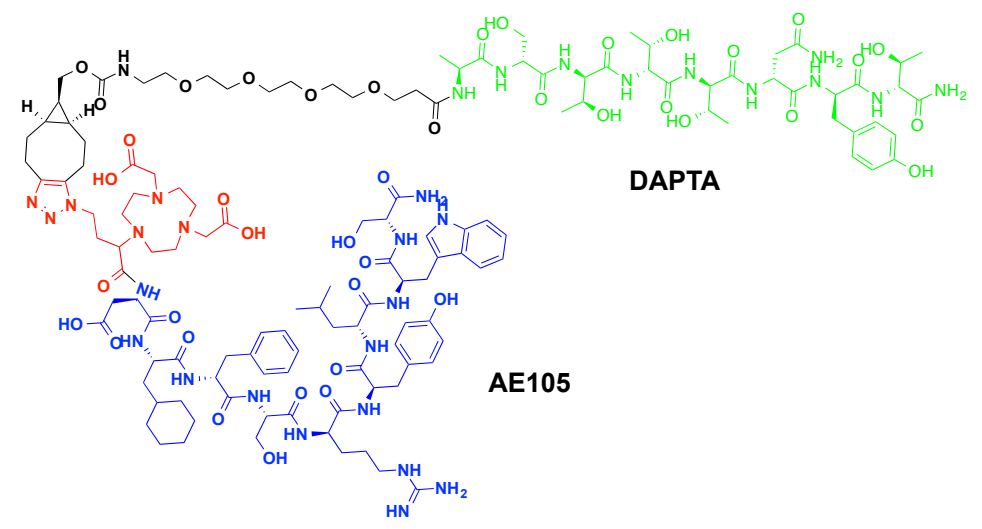

HPLC conditions: Luna C-18 150*4.6 mm column, $1.5 \mathrm{ml} / \mathrm{min}, 0 \sim 3 \mathrm{~min} 20 \% \mathrm{~B}, 3 \sim 28 \mathrm{~min}$ from $20 \% \mathrm{~B}$ to $50 \% \mathrm{~B}$. Retention time $21.6 \mathrm{~min}$. Yield, $>95 \%$; purity, $>95 \%$. MALDI-MS: observed, $m / z(\mathrm{M}+\mathrm{H})^{+}=2864.2$, calculated, $(\mathrm{M}+\mathrm{H})^{+}=2859.4$

\section{LLP2A-PEG 8 -click-NOTA-AE105 (8e)}




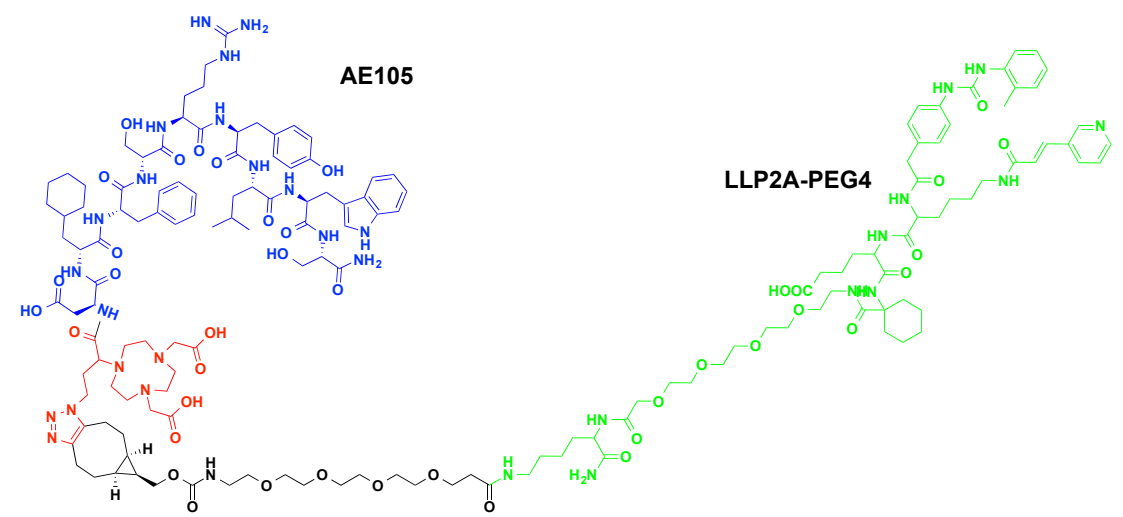

HPLC conditions: Luna C-18 150*4.6 mm column, $1.5 \mathrm{ml} / \mathrm{min}, 0 \sim 3 \mathrm{~min} 20 \% \mathrm{~B}, 3 \sim 33 \mathrm{~min}$ from $20 \% \mathrm{~B}$ to $50 \% \mathrm{~B}$. Retention time: $22.43 \mathrm{~min}$. Yield, $>95 \%$; purity, $>95 \%$. MALDI-MS: observed, $m / z(\mathrm{M}+\mathrm{Na})^{+}=3179.2$, calculated, $(\mathrm{M}+\mathrm{Na})^{+}=3174.7$

\subsection{Synthesis of homodimer and multimodality probe using scaffold $\mathrm{N}_{3}-\mathrm{NO}^{\text {t }} \mathrm{B}_{2}$ via SPPS}

\section{Resin-AE105-NO ${ }^{t} \mathrm{~B}_{2}-\mathrm{NH}_{2}$}

Resin-AE105-NO' $\mathrm{B}_{2}-\mathrm{N}_{3}$ was swelled in $1 \mathrm{ml} \mathrm{DMF}$, and then $\mathrm{PPh}_{3}(3$ eq.) in $\mathrm{MeOH}$ was added. The mixture was reacted for $12 \mathrm{~h}$ at room temperature, followed by thorough washing with DMF to yield resin-AE105-NO ${ }^{\mathrm{t}} \mathbf{B}_{2}-\mathbf{N H}_{2}$ A small amount of resin was cleaved and checked by LC-MS. The result showed complete conversion. ESI-MS: observed, $\mathrm{m} / \mathrm{z}(\mathrm{M}+\mathrm{H})^{+}=1553.150$, calculated, $(\mathrm{M}+\mathrm{H})^{+}=1553.807$.

\section{AE105-nonclick-NOTA-AE105 (9a)}

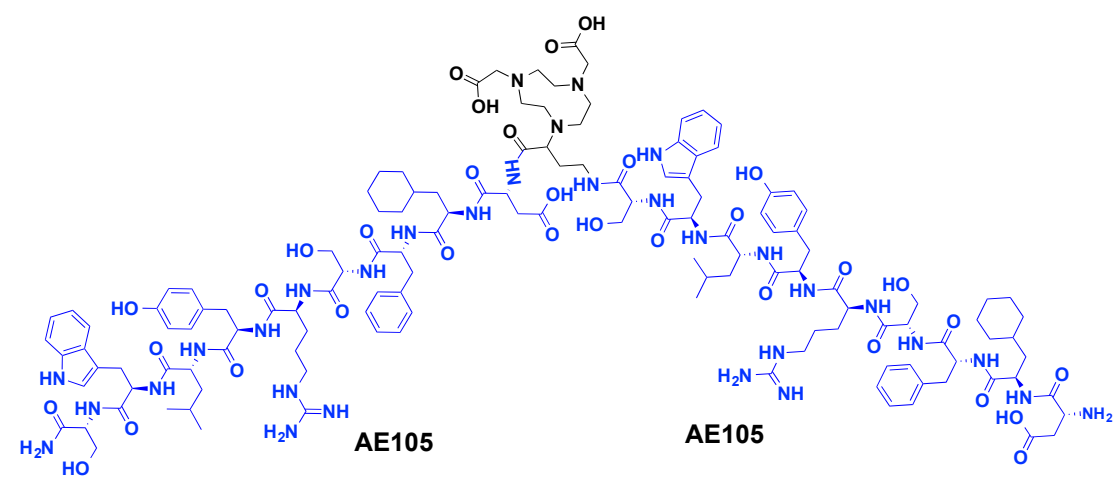

9a was prepared by coupling resin-AE105-NO${ }^{t} \mathbf{B}_{2}-\mathbf{N H}_{\mathbf{2}}$ with the amino acids in the following order: Fmoc-Ser, Fmoc-Trp, Fmoc-Leu, Fmoc-Tyr, Fmoc-(D)Arg, Fmoc-(D)Ser, Fmoc-Phe, Fmoc-Cha and Fmoc-Asp, using standard Fmoc-SPPS. 9a was then cleavage from resin by TFA/ $\mathrm{H}_{2} \mathrm{O} / \mathrm{TIS} /$ phenol (90:5:2.5:2.5) and checked by LC-MS and HPLC ( 70\% purity before HPLC purification). HPLC conditions: Luna C-18 150*4.6 mm column, $1.5 \mathrm{ml} / \mathrm{min}, 0 \sim 3 \min 20 \% \mathrm{~B}, 3 \sim 33 \mathrm{~min}$ from $20 \% \mathrm{~B}$ to $60 \% \mathrm{~B}$. Retention time $28.69 \mathrm{~min}$. Isolation yield, $50 \%$; purity $>95 \%$. ESI-MS: observed, $\mathrm{m} / \mathrm{z}(\mathrm{M}+2 \mathrm{H})^{2+}=1379.935$, calculated, $(\mathrm{M}+2 \mathrm{H})^{2+}=1381.211$.

\section{Cy3-nonclick-NOTA-AE105 (9b)}




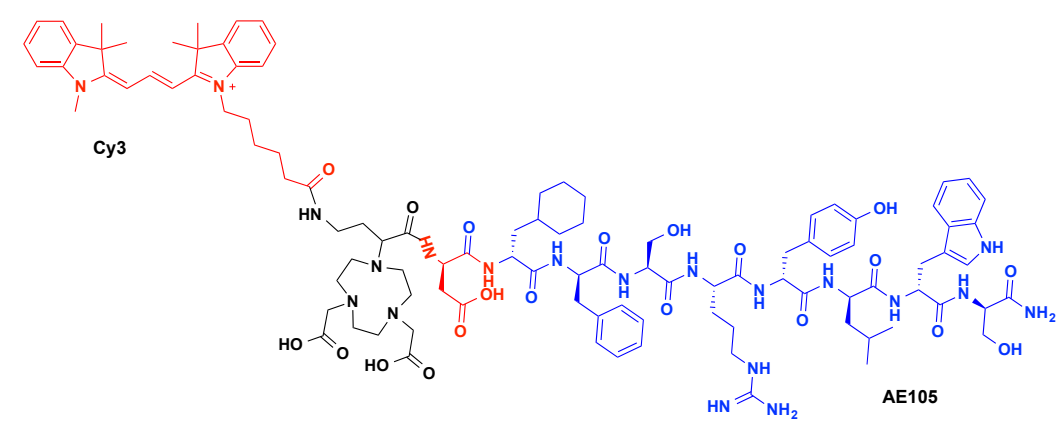

To resin-AE105-NO' $\mathbf{B}_{2}-\mathbf{N H}_{2}$ was added Cy3-NHS* (3 eq.) in DMF and the resulting mixture was reacted for $4 \mathrm{~h}$ at room temperature. 9b was then obtained after cleavage from the resin and purification with HPLC ( $\sim 85 \%$ purity before HPLC purification, retention time 28.5 min). HPLC conditions: Luna C-18 150*4.6 mm column, 1.5 $\mathrm{ml} / \mathrm{min}, 0 \sim 3 \min 20 \% \mathrm{~B}, 3 \sim 33 \min$ from $20 \% \mathrm{~B}$ to $50 \%$ B. Isolation yield, $62 \%$; purity $>95 \%$. ESI-MS: observed, $\mathrm{m} / \mathrm{z}(\mathrm{M}+2 \mathrm{H})^{2+}=995.994$, calculated, $(\mathrm{M}+2 \mathrm{H})^{2+}=997.039$.

*Cy3 (Cyanine3), a fluorescent dye. 


\section{DFT Computation:}

All calculations were performed using Gaussian09 suite of program. ${ }^{[3]}$ Density functional theory method was used, employing uB3LYP hybrid functional. ${ }^{[4]}$ Geometry optimization was done using a combined basis set $6-31+\mathrm{G}(\mathrm{d}, \mathrm{p})$. Frequency calculation was done at the same level of theory as geometry optimization, to confirm the stationary points to be minima. Single point energy calculations were done using B3LYP method at a larger basis set 6-311++G(d,p). Solvent effect was accounted for using self-consistent reaction field (SCRF) method, using SMD model and UAKS radii. ${ }^{[5]}$ Water was used as the solvent.

Two proposed models with the coordination of $\mathrm{Cu}(\mathrm{II})$ with an additional acetate ion (from $\mathrm{NH}_{4} \mathrm{OAc}$ buffer) or the $\mathrm{N}$ atom of triazole were optimized. The energies were calculated at ub3lyp/6-31G++(d,p) level (water as solvent). The model B, with $10.2 \mathrm{kcal} / \mathrm{mol}$ lower energy than model A, should be the more stable configuration. These results suggest that the introduction of triazole group to this coordination system may promote the formation of a more stable complex with $\mathrm{Cu}$ (II).

Another DFT calculation was performed to determine whether the triazole in the structure was capable of forming a coordinate bond with Ga(III). As shown in Fig. S1, the triazole group can form a coordinate bond with Ga(III), thus increasing the stability of its complex.

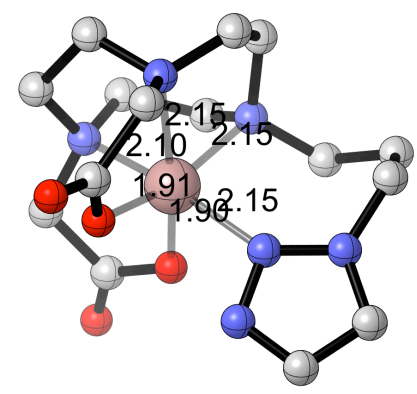

Figure S1. DFT optimized structure of the hypothetical model of triazole- $\left(\mathrm{Ga}^{3+}\right)$ NOTA complex

\section{DFT computational data:}

$\mathrm{AC}$

Zero-point correction=

Thermal correction to Energy=

Thermal correction to Enthalpy=

Thermal correction to Gibbs Free Energy=

$\mathrm{E}($ sov $)=-228.716173160 \quad \mathrm{~A} . \mathrm{U}$.
0.047928 (Hartree/Particle)

0.052405

0.053349

0.019841
Center Atomic Atomic

Number Number Type
Coordinates (Angstroms)

$\mathrm{X}$

Y
Z 


$\begin{array}{cccccc}1 & 6 & 0 & 1.353828 & -0.046981 & -0.001555 \\ 2 & 1 & 0 & 1.748243 & 0.575957 & -0.814584 \\ 3 & 1 & 0 & 1.728725 & -1.071203 & -0.105452 \\ 4 & 1 & 0 & 1.728132 & 0.378706 & 0.939274 \\ 6 & 6 & 0 & -0.209086 & 0.001091 & -0.003556 \\ 7 & 8 & 0 & -0.802383 & -1.112278 & 0.000725 \\ & 8 & 0 & -0.706811 & 1.161263 & 0.000703\end{array}$

Mode A

\begin{tabular}{|c|c|c|c|c|c|}
\hline Zero-poin & nt correction= & & & 0.462104 & (Hartree/Particle) \\
\hline Thermal c & correction to $\mathrm{E}$ & Energy= & & 0.49218 & \\
\hline Thermal c & correction to $\mathrm{E}$ & Enthalpy= & & 0.49312 & \\
\hline Thermal c & correction to $\mathrm{G}$ & Gibbs Fre & ee Energy= & $0.397 \varepsilon$ & 379 \\
\hline $\mathrm{E}(\mathrm{s} O \mathrm{v})=$ & $=-3085.11102459$ & A. U & & & \\
\hline Center & Atomic & Atomic & $\mathrm{Coc}$ & rdinates (A & ngstroms) \\
\hline Number & Number & Type & $\mathrm{x}$ & Y & Z \\
\hline 1 & 29 & 0 & -1.570764 & 0.139830 & 0.274888 \\
\hline 2 & 7 & 0 & -1.703512 & 0.106822 & -1.862463 \\
\hline 3 & 7 & 0 & -2.088090 & -1.924429 & 0.039024 \\
\hline 4 & 6 & 0 & -2.614053 & -2.164274 & -1.329388 \\
\hline 5 & 6 & 0 & -2.817654 & -0.847209 & -2.091167 \\
\hline 6 & 7 & 0 & 0.694097 & -1.043552 & -0.435254 \\
\hline 7 & 6 & 0 & 0.814452 & -0.291213 & -1.678855 \\
\hline 8 & 6 & 0 & -0.454768 & -0.307704 & -2.552419 \\
\hline 9 & 6 & 0 & -0.910593 & -2.773363 & 0.346239 \\
\hline 10 & 6 & 0 & 0.335163 & -2.450438 & -0.505941 \\
\hline 11 & 6 & 0 & -2.135652 & 1.488752 & -2.197307 \\
\hline 12 & 6 & 0 & -3.288916 & 1.983167 & -1.267340 \\
\hline 13 & 8 & 0 & -3.921766 & 2.970465 & -1.675730 \\
\hline
\end{tabular}




\begin{tabular}{|c|c|c|c|c|c|}
\hline 14 & 8 & 0 & -3.450396 & 1.314402 & -0.192796 \\
\hline 15 & 6 & 0 & -2.599605 & -1.299531 & 2.395912 \\
\hline 16 & 6 & 0 & -3.103028 & -2.019773 & 1.116426 \\
\hline 17 & 8 & 0 & -1.781666 & -0.320992 & 2.178416 \\
\hline 18 & 8 & 0 & -3.004374 & -1.695103 & 3.490269 \\
\hline 19 & 6 & 0 & 3.109966 & -0.914303 & 0.474416 \\
\hline 20 & 6 & 0 & 3.802394 & 0.196868 & -0.332117 \\
\hline 21 & 7 & 0 & 6.008215 & -0.662984 & -0.953828 \\
\hline 22 & 7 & 0 & 7.257719 & -0.526247 & -0.583317 \\
\hline 23 & 6 & 0 & 6.040506 & 0.841366 & 0.684852 \\
\hline 24 & 6 & 0 & 7.318155 & 0.390240 & 0.423573 \\
\hline 25 & 1 & 0 & -3.566844 & -2.707717 & -1.285687 \\
\hline 26 & 1 & 0 & -1.915696 & -2.814647 & -1.863625 \\
\hline 27 & 1 & 0 & -2.945711 & -1.053530 & -3.166956 \\
\hline 28 & 1 & 0 & -3.721849 & -0.362879 & -1.724243 \\
\hline 29 & 1 & 0 & 1.637561 & -0.650524 & -2.328817 \\
\hline 30 & 1 & 0 & 1.026400 & 0.741462 & -1.390805 \\
\hline 31 & 1 & 0 & -0.273073 & 0.347728 & -3.414555 \\
\hline 32 & 1 & 0 & -0.602807 & -1.311155 & -2.966405 \\
\hline 33 & 1 & 0 & -1.171513 & -3.839413 & 0.227793 \\
\hline 34 & 1 & 0 & -0.669556 & -2.610620 & 1.399277 \\
\hline 35 & 1 & 0 & 1.150104 & -3.103284 & -0.151838 \\
\hline 36 & 1 & 0 & 0.167588 & -2.738634 & -1.548663 \\
\hline 37 & 1 & 0 & -2.457987 & 1.554456 & -3.246741 \\
\hline 38 & 1 & 0 & -1.279305 & 2.150974 & -2.046962 \\
\hline 39 & 1 & 0 & -4.006535 & -1.499805 & 0.781259 \\
\hline 40 & 1 & 0 & -3.357308 & -3.063108 & 1.348818 \\
\hline 41 & 1 & 0 & 3.562661 & -0.930777 & 1.474387 \\
\hline 42 & 1 & 0 & 3.318472 & -1.890713 & 0.019337 \\
\hline 43 & 1 & 0 & 3.592034 & 0.118436 & -1.399654 \\
\hline 44 & 1 & 0 & 3.462512 & 1.178437 & 0.012016 \\
\hline 45 & 1 & 0 & 5.636051 & 1.559390 & 1.381650 \\
\hline 46 & 1 & 0 & 8.254760 & 0.668562 & 0.882836 \\
\hline
\end{tabular}




\begin{tabular}{|c|c|c|c|c|c|}
\hline 47 & 6 & 0 & 1.593520 & -0.671448 & 0.659770 \\
\hline 48 & 1 & 0 & 1.261019 & -1.222517 & 1.545625 \\
\hline 49 & 1 & 0 & 1.425303 & 0.386056 & 0.878429 \\
\hline 50 & 6 & 0 & -1.094754 & 2.956513 & 2.210864 \\
\hline 51 & 1 & 0 & -1.970606 & 3.307570 & 1.656100 \\
\hline 52 & 1 & 0 & -0.723083 & 3.740150 & 2.874510 \\
\hline 53 & 1 & 0 & -1.420861 & 2.091079 & 2.797354 \\
\hline 54 & 6 & 0 & -0.004467 & 2.523244 & 1.242668 \\
\hline 55 & 8 & 0 & 1.153993 & 2.963895 & 1.335827 \\
\hline 56 & 8 & 0 & -0.346931 & 1.674410 & 0.315645 \\
\hline 57 & 7 & 0 & 5.260936 & 0.164388 & -0.194212 \\
\hline
\end{tabular}

Mode B

\section{Zero-point correction=}

Thermal correction to Energy=

Thermal correction to Enthalpy=

Thermal correction to Gibbs Free Energy=

$E($ SOV $)=-2856.39301344 \quad$ A.U.

\author{
0.412869 (Hartree/Particle) \\ 0.436562 \\ 0.437506 \\ 0.359921
}

\begin{tabular}{|c|c|c|c|c|c|}
\hline Center & Atomic & Atomic & & Ees & (Angstroms) \\
\hline Number & Number & Type & $\mathrm{X}$ & $\mathrm{Y}$ & Z \\
\hline
\end{tabular}

$\begin{array}{llllll}1 & 29 & 0 & 0.018968 & 0.633753 & -0.541410 \\ 2 & 7 & 0 & -1.434327 & -2.052127 & -0.055066 \\ 3 & 7 & 0 & -1.992064 & 0.888490 & 0.025041 \\ 4 & 6 & 0 & -2.916660 & -0.090682 & -0.608070 \\ 5 & 6 & 0 & -2.793516 & -1.528500 & -0.074197 \\ 6 & 7 & 0 & -0.110405 & -0.471675 & 2.013913 \\ 7 & 6 & 0 & -0.850563 & -1.701852 & 2.353001 \\ 8 & 6 & 0 & -1.021743 & -2.695184 & 1.181878 \\ 9 & 6 & 0 & -2.145326 & 0.944696 & 1.521190 \\ 10 & 6 & 0 & -0.861088 & 0.748083 & 2.344622\end{array}$




\begin{tabular}{|c|c|c|c|c|c|}
\hline 11 & 6 & 0 & -1.027020 & -2.680862 & -1.301796 \\
\hline 12 & 6 & 0 & -0.558266 & -1.705622 & -2.408838 \\
\hline 13 & 8 & 0 & -0.614409 & -2.097672 & -3.572307 \\
\hline 14 & 8 & 0 & -0.079472 & -0.557875 & -2.038318 \\
\hline 15 & 6 & 0 & -1.006984 & 3.147179 & -0.138660 \\
\hline 16 & 6 & 0 & -2.192152 & 2.249799 & -0.550060 \\
\hline 17 & 8 & 0 & 0.106494 & 2.487390 & 0.028227 \\
\hline 18 & 8 & 0 & -1.161743 & 4.353133 & 0.001506 \\
\hline 19 & 6 & 0 & 2.184010 & -1.525119 & 2.038913 \\
\hline 20 & 6 & 0 & 2.329605 & -1.600184 & 0.512154 \\
\hline 21 & 7 & 0 & 2.900978 & -0.397222 & -0.092375 \\
\hline 22 & 7 & 0 & 2.108778 & 0.600682 & -0.539637 \\
\hline 23 & 7 & 0 & 2.852482 & 1.547986 & -1.034773 \\
\hline 24 & 6 & 0 & 4.196450 & -0.068536 & -0.306004 \\
\hline 25 & 6 & 0 & 4.149700 & 1.173219 & -0.909428 \\
\hline 26 & 1 & 0 & -2.707335 & -0.070935 & -1.679995 \\
\hline 27 & 1 & 0 & -3.958220 & 0.240256 & -0.467851 \\
\hline 28 & 1 & 0 & -3.212219 & -1.585385 & 0.935036 \\
\hline 29 & 1 & 0 & -3.452106 & -2.153956 & -0.701656 \\
\hline 30 & 1 & 0 & -1.840752 & -1.425581 & 2.729704 \\
\hline 31 & 1 & 0 & -0.366641 & -2.232720 & 3.187293 \\
\hline 32 & 1 & 0 & -0.068230 & -3.194447 & 0.989395 \\
\hline 33 & 1 & 0 & -1.718756 & -3.488518 & 1.518301 \\
\hline 34 & 1 & 0 & -2.898192 & 0.212226 & 1.817136 \\
\hline 35 & 1 & 0 & -2.552507 & 1.923568 & 1.796824 \\
\hline 36 & 1 & 0 & -0.204225 & 1.601913 & 2.172139 \\
\hline 37 & 1 & 0 & -1.161592 & 0.767376 & 3.409875 \\
\hline 38 & 1 & 0 & -1.818448 & -3.309953 & -1.738660 \\
\hline 39 & 1 & 0 & -0.176984 & -3.346078 & -1.109883 \\
\hline 40 & 1 & 0 & -2.207143 & 2.168116 & -1.642676 \\
\hline 41 & 1 & 0 & -3.141577 & 2.690980 & -0.223922 \\
\hline 42 & 1 & 0 & 3.169626 & -1.378004 & 2.497113 \\
\hline 43 & 1 & 0 & 1.840637 & -2.511479 & 2.373704 \\
\hline
\end{tabular}




$\begin{array}{llllll}44 & 1 & 0 & 2.974940 & -2.436935 & 0.231714 \\ 45 & 1 & 0 & 1.362204 & -1.740243 & 0.030785 \\ 46 & 1 & 0 & 5.010545 & -0.721483 & -0.032297 \\ 47 & 1 & 0 & 4.953687 & 1.801498 & -1.259978 \\ 48 & 6 & 0 & 1.250868 & -0.424277 & 2.564833 \\ 49 & 1 & 0 & 1.242646 & -0.488350 & 3.669720 \\ 50 & 1 & 0 & 1.671629 & 0.553598 & 2.309265\end{array}$

\section{triazole- $\left(\mathrm{Ga}^{3+}\right)$ NOTA}

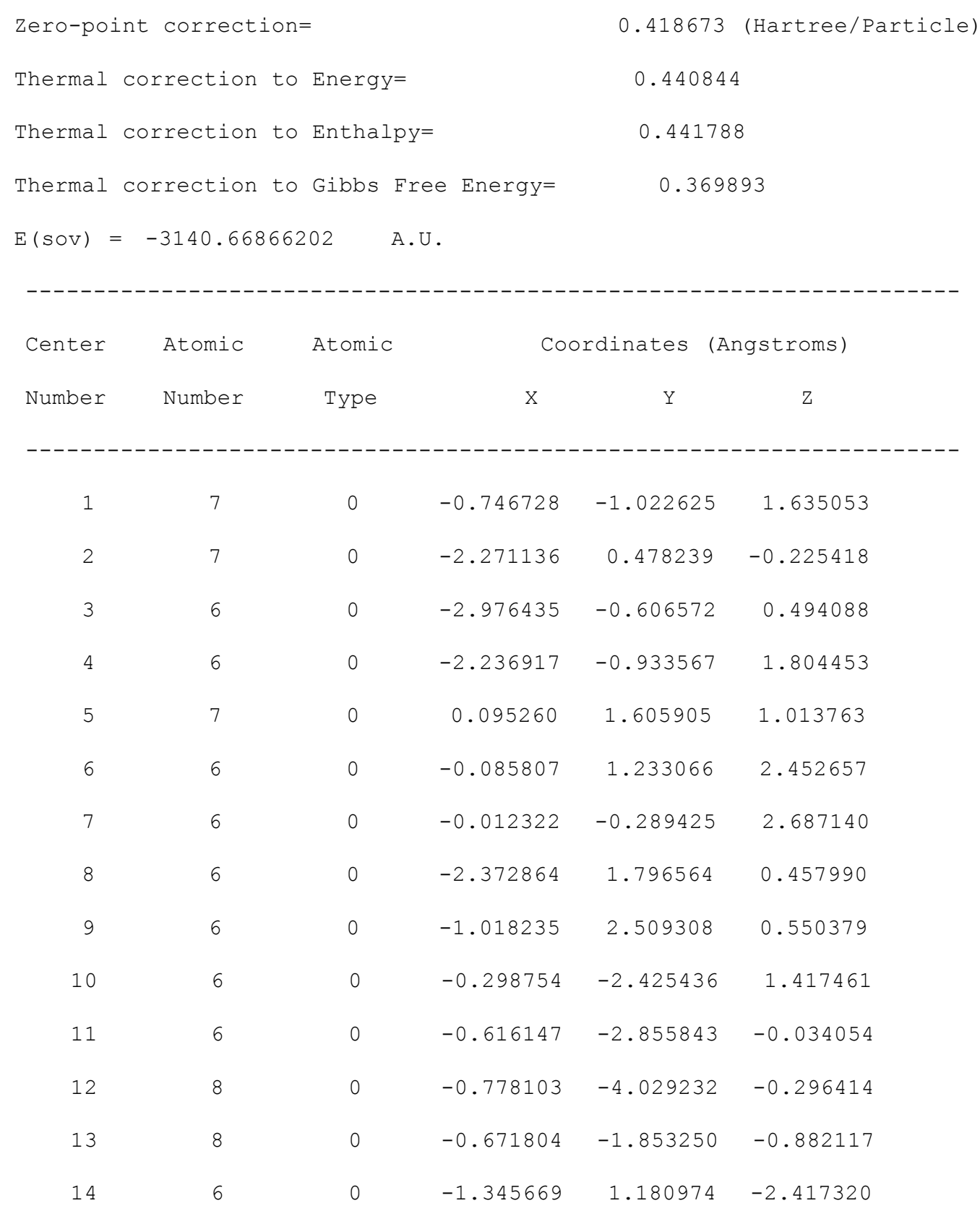




\begin{tabular}{|c|c|c|c|c|c|}
\hline 15 & 6 & 0 & -2.555966 & 0.558075 & -1.686365 \\
\hline 16 & 8 & 0 & -0.184512 & 0.954054 & -1.823357 \\
\hline 17 & 8 & 0 & -1.496118 & 1.814389 & -3.439816 \\
\hline 18 & 6 & 0 & 2.689830 & 1.926224 & 1.349350 \\
\hline 19 & 6 & 0 & 3.200628 & 0.482466 & 1.230743 \\
\hline 20 & 7 & 0 & 3.045497 & -0.115834 & -0.092282 \\
\hline 21 & 7 & 0 & 1.836467 & -0.531205 & -0.546282 \\
\hline 22 & 7 & 0 & 1.994557 & -1.099261 & -1.713662 \\
\hline 23 & 6 & 0 & 3.991892 & -0.450412 & -0.995929 \\
\hline 24 & 6 & 0 & 3.304741 & -1.072013 & -2.025452 \\
\hline 25 & 1 & 0 & -2.990252 & -1.475265 & -0.162979 \\
\hline 26 & 1 & 0 & -4.013707 & -0.335330 & 0.725438 \\
\hline 27 & 1 & 0 & -2.439968 & -0.161152 & 2.548835 \\
\hline 28 & 1 & 0 & -2.618129 & -1.874479 & 2.213142 \\
\hline 29 & 1 & 0 & -1.060217 & 1.600986 & 2.778492 \\
\hline 30 & 1 & 0 & 0.651476 & 1.735582 & 3.083071 \\
\hline 31 & 1 & 0 & 1.021659 & -0.630848 & 2.647458 \\
\hline 32 & 1 & 0 & -0.389651 & -0.520705 & 3.691048 \\
\hline 33 & 1 & 0 & -2.787222 & 1.635482 & 1.455035 \\
\hline 34 & 1 & 0 & -3.076600 & 2.448144 & -0.070818 \\
\hline 35 & 1 & 0 & -0.727041 & 2.887466 & -0.428826 \\
\hline 36 & 1 & 0 & -1.103614 & 3.364206 & 1.232398 \\
\hline 37 & 1 & 0 & -0.753568 & -3.121014 & 2.127914 \\
\hline 38 & 1 & 0 & 0.788877 & -2.468271 & 1.536394 \\
\hline 39 & 1 & 0 & -2.680996 & -0.460033 & -2.065966 \\
\hline 40 & 1 & 0 & -3.461279 & 1.134267 & -1.895726 \\
\hline 41 & 1 & 0 & 3.436062 & 2.594709 & 0.904791 \\
\hline 42 & 1 & 0 & 2.681970 & 2.170910 & 2.417167 \\
\hline 43 & 1 & 0 & 4.266488 & 0.456376 & 1.465377 \\
\hline 44 & 1 & 0 & 2.710978 & -0.184395 & 1.940974 \\
\hline 45 & 1 & 0 & 5.039092 & -0.240203 & -0.839075 \\
\hline 46 & 1 & 0 & 3.671390 & -1.498092 & -2.946625 \\
\hline 47 & 6 & 0 & 1.375074 & 2.334962 & 0.675543 \\
\hline
\end{tabular}




$\begin{array}{cccccc}48 & 1 & 0 & 1.231801 & 3.394067 & 0.922891 \\ 49 & 1 & 0 & 1.470675 & 2.270035 & -0.411984 \\ 50 & 31 & 0 & -0.250311 & -0.107964 & -0.245068\end{array}$




\section{General radiolabeling procedure and in vitro evaluation}

\section{Radio-HPLC method:}

Two elution buffers ( $0.1 \mathrm{v} \%$ TFA in de-ionized water as elution buffer $\mathbf{A}$ and $0.1 \mathrm{v} \%$ TFA in acetonitrile as elution buffer B) were used in radio-HPLC experiments. Flow, $2 \mathrm{ml} / \mathrm{min} ; 0-5 \min 0 \% \mathrm{~B}, 5-7 \mathrm{~min}$ from $0 \% \mathrm{~B}$ to $90 \% \mathrm{~B}$; 7-13.5min, $90 \% \mathrm{~B}$; $14 \mathrm{~min} 0 \% \mathrm{~B})$.

\section{Cu-64 labeling procedure:}

The ${ }^{64} \mathrm{Cu}$-labeling of all conjugates were performed in $0.1 \mathrm{M} \mathrm{NH}_{4} \mathrm{OAc}$ buffer $(\mathrm{pH}=4)$ as follows: $\sim 10 \mu \mathrm{L}$ of the conjugate stock solution $(50 \mathrm{nmol} / \mathrm{mL})$ was added to $100 \mu \mathrm{L}$ buffer in a $1.5 \mathrm{~mL}$ tube, and then $500 \sim 1000 \mu \mathrm{Ci}$ of ${ }^{64} \mathrm{Cu}^{2+}$ in $50 \mu \mathrm{L}$ buffer was added. The mixture was vortexed for $10 \mathrm{sec}$, and incubated in a thermomixer at $40{ }^{\circ} \mathrm{C}$ for $0.5 \mathrm{~h}$. The radiolabeling yield was determined by radio-HPLC, and usually quantitative labeling ( $\geq 98 \%$ radio-purity) could be obtained.

\section{Ga-68 labeling procedure:}

The ${ }^{68} \mathrm{Ga}$-labeling of all conjugates were performed in $0.1 \mathrm{M} \mathrm{NaOAc}$ buffer $(\mathrm{pH}=4)$ as follows: $\sim 10 \mu \mathrm{L}$ of the conjugate stock solution $(50 \mathrm{nmol} / \mathrm{mL})$ was added to $100 \mu \mathrm{L}$ buffer in a $1.5 \mathrm{~mL}$ tube, and then $500 \sim 1000 \mu \mathrm{Ci}$ of ${ }^{68} \mathrm{Ga}^{2+}$ in $50 \mu \mathrm{L}$ buffer was added. The mixture was vortexed for $10 \mathrm{sec}$, and incubated in a thermomixer at $70{ }^{\circ} \mathrm{C}$ for $10 \mathrm{~min}$. The radiolabeling yield was determined by radio-HPLC, and usually quantitative labeling ( $\geq 98 \%$ radio-purity) could be obtained.

Serum stability measurement: ${ }^{64} \mathrm{Cu}$-labeled conjugate $(\sim 100 \mu \mathrm{Ci})$ was mixed with $0.5 \mathrm{~mL}$ human serum, and the resulting mixture was incubated at $37{ }^{\circ} \mathrm{C}$ for 1 day $\left(2 \mathrm{~h}\right.$ for ${ }^{68} \mathrm{Ga}$ labeled conjugates). After incubation, plasma protein was precipitated with $0.5 \mathrm{~mL}$ acetonitrile and centrifuged at $14000 \mathrm{RPM}$ for $5 \mathrm{~min}$. The supernatant was collected and more than $95 \%$ activity was recovered determined by a dose calibrator. The radio-purity was determined by radio-HPLC. Free ${ }^{64} \mathrm{Cu}^{2+}$ or free ${ }^{68} \mathrm{Ga}^{3+}$ comes out at $\sim 1.5 \mathrm{~min}$ and the radiolabeled conjugates come out at 7 8 $\mathrm{min}$. More than $95 \%$ intact radiolabeled conjugates were observed. 

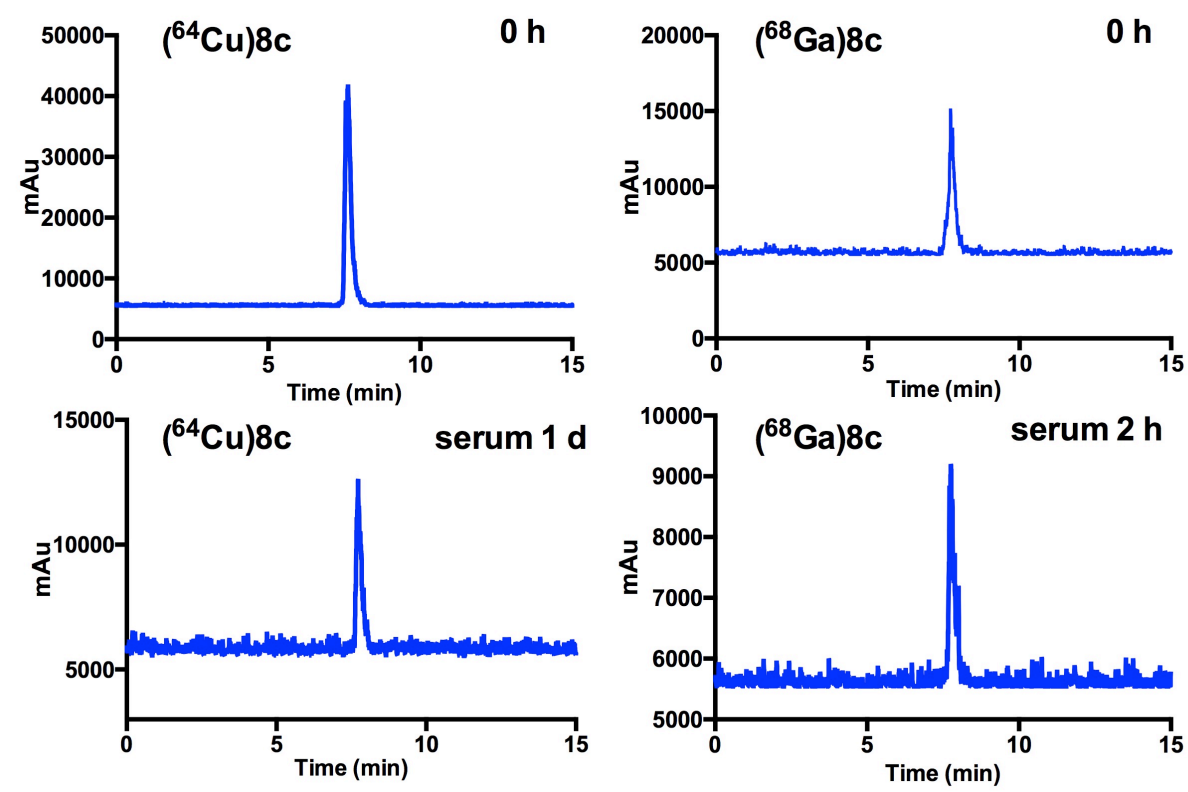

Figure S2. Radio-HPLC results of $\left({ }^{64} \mathrm{Cu}\right) \mathbf{8 c}$ and $\left({ }^{68} \mathrm{Ga}\right) \mathbf{8 c}$ after being incubated in human serum for $1 \mathrm{~d}$ and $2 \mathrm{hr}$, respectively.

\section{Cell studies}

U87MG cell line was purchased from the American Tissue Culture Collection (ATCC). All cell handling was aseptically performed in a laminar flow hood. The U87MG cells were cultured in Dulbecco's Modified Eagle Medium, supplemented with 10\% FBS, penicillin (100 unit/mL), streptomycin $(100 \mu \mathrm{g} / \mathrm{mL})$ L-glutamine $(300$ $\mu \mathrm{g} / \mathrm{mL})$ and sodium pyruvate $(100 \mathrm{mg} / \mathrm{mL})$, glucose $(4.5 \mathrm{~g} / \mathrm{L})$ and maintained at $37^{\circ} \mathrm{C}, 5 \% \mathrm{CO}_{2}$.

Saturation binding assay: Cells were seeded in 24-well plates (100,000 cells per well) $24 \mathrm{~h}$ before the experiment. Before the experiment, cells were washed with $1 \mathrm{~mL}$ HBSS twice and $0.5 \mathrm{~mL}$ binding media (HBSS with $0.1 \%$ BSA and $\left.1 \mathrm{mM} \mathrm{Mn}^{2+}\right)$ was added to each well. Then block agent $(10 \mu \mathrm{g}$ AE105+ $10 \mu \mathrm{g}$ RGD) was added to half of the wells as cold block to determine in vitro non-specific binding, followed by $\left({ }^{64} \mathrm{Cu}\right) \mathbf{8 c}$ in increasing concentrations (1-100 nM). The samples were incubated for $2 \mathrm{~h}$ on ice $\left(4{ }^{\circ} \mathrm{C}\right)$. After incubation, the radioactive media was removed. Cell pellets were rinsed with ice cold binding buffer $(1 \mathrm{~mL})$ twice and dissolved in $0.5 \%$ SDS solution. The radioactivity in each fraction was measured in a gamma counter. The protein content of each cell lysate sample was determined (BCA Protein Assay Kit, Pierce). The measured radioactivity associated with the cells was normalized to the amount of cell protein present ( $\mathrm{fmol} / \mathrm{mg})$. 
A

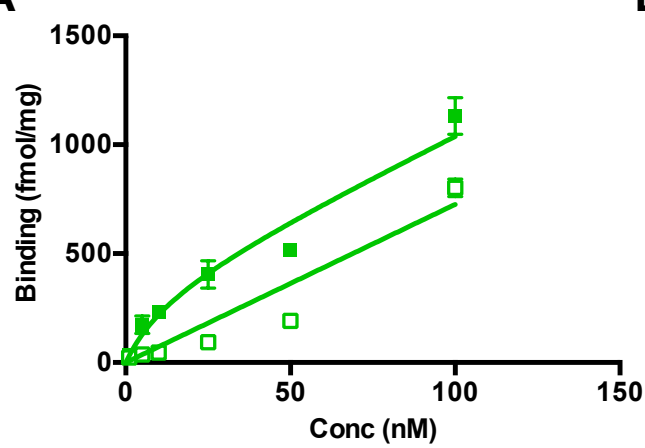

B

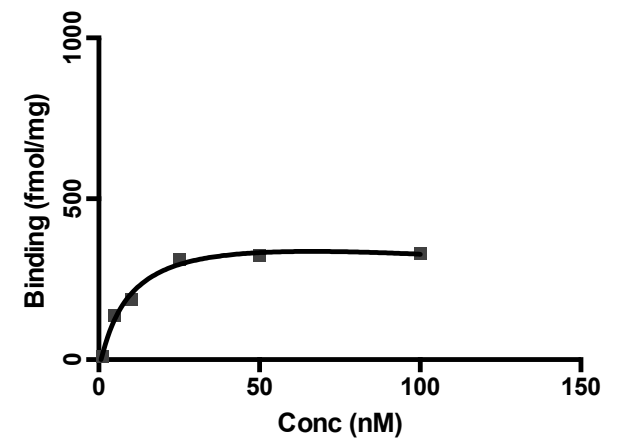

Figure S3 Total (solid square) and nonspecific (blank square) binding of $\left({ }^{64} \mathrm{Cu}\right) \mathbf{8 c}$ in U87MG cell (A); Baseline-corrected of total and nonspecific binding of $\left({ }^{64} \mathrm{Cu}\right) \mathbf{8 c}$ in U87MG cell (B)

Cell stain study: Cells were seeded in an 8 well chamber slide $(100,000$ cells per well) $24 \mathrm{~h}$ prior to the experiment. Before the experiment, cells were washed twice with PBS and added culture media. Then block agent (10 $\mu \mathrm{g}$ AE105) was added to half of the wells as cold block to determine in vitro non-specific uptake and incubated for $1 \mathrm{~h}$. Then Cy3-noclick-NOTA-AE105 (9b) (10 pmol per well) was added to each well and further incubated for $2 \mathrm{~h}$. Media was then removed and cells were washed twice with PBS. After fixing the cells using 1\% Paraformaldehyde, the nucleus was stained by DAPI. The slide was sealed and observed under fluorescence microscopy (40 X, oil). 


\section{In vivo evaluation}

\section{Animal Model}

Four-week old female NCr nude mice purchased from Taconic Labs (Hudson, NY) were used in this study. All animal studies were performed under the Guide for the Care and Use of Laboratory Animals under the auspices of Division of Laboratory Animal Resources (DLAR) of the University of Pittsburgh. (Animal protocol \# 13051860). For xenograft U87MG tumor mice, nude mice were injected subcutaneously at the right shoulder with five million cells in $150 \mu \mathrm{L}$ PBS and BD matrigel (1:1).

Metabolism: The procedure was followed and modified according to the literature. ${ }^{7}$ Briefly, $0.5 \sim 1 \mathrm{mCi}\left({ }^{64} \mathrm{Cu}\right) \mathbf{8 c}$ and $\left({ }^{64} \mathrm{Cu}\right)$ NODAGA-AE105 were injected to nude mice. The mice were sacrificed at $4 \mathrm{~h}$ postinjection, and the liver was immediately excised and placed on ice. The liver was homogenized in 65:35 ethanol/ $\mathrm{NH}_{4} \mathrm{OAc}(0.1 \mathrm{M}$, pH 5.5) using a glass tissue homogenizer followed by a 1-min tip sonication using a Sonifier 185 cell disruptor (Branson, Danbury, Connecticut). The insoluble protein and cellular debris were removed by centrifugation at $23500 \mathrm{~g}$ for $30 \mathrm{~min}$ at $4{ }^{\circ} \mathrm{C}$. The supernatant was analyzed by size-exclusion fast protein liquid chromatography (FPLC) on a Superose 12 10/300 GL column (Amersham Biosciences, Uppsala, Sweden) eluted with 1X DPBS $(0.6 \mathrm{~mL} / \mathrm{min})$.
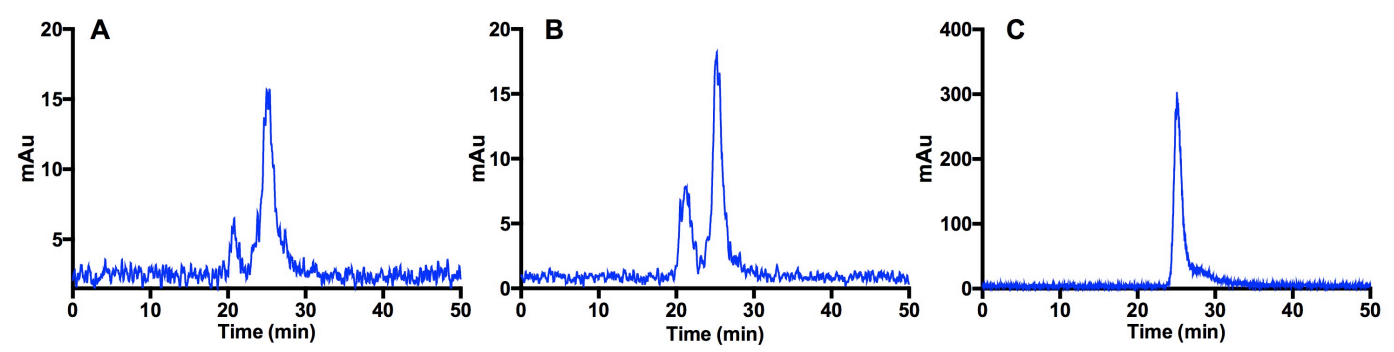

Figure S4. FPLC of liver extracts from female nude mice after $4 \mathrm{~h}$ injection of $\left({ }^{64} \mathrm{Cu}\right) \mathbf{8 c}(\mathrm{A})$ and $\left({ }^{64} \mathrm{Cu}\right)$ NODAGA-AE105 (B), and FPLC of $\left({ }^{64} \mathrm{Cu}\right) \mathbf{8 c}(\mathbf{C})$.

Micro PET/CT imaging: U87MG xenograft tumor-bearing mice ( $\mathrm{n}=3 \sim 4$ per group) were injected intravenously (lateral tail vein) with $100 \sim 150 \mu \mathrm{Ci}\left({ }^{64} \mathrm{Cu}\right) \mathbf{8 c}$, and $\left({ }^{64} \mathrm{Cu}\right) \mathbf{8 c}$ plus blocking agents $[100 \mu \mathrm{g} \mathrm{AE} 105$ and $100 \mu \mathrm{g}$ c(RGDyK)]. For comparison, NODAGA-AE105 and NODAGA-RGD were also prepared, radiolabeled with Cu-64 and injected into U87MG xenograft tumor-bearing mice. At $1 \mathrm{~h}$ and $4 \mathrm{~h}$ p.i., mice were anesthetized with $2 \%$ isoflurane and small-animal PET/CT was performed. Static images were collected for 15 min using a small animal Inveon PET/CT scanner (Siemens Medical Solution), with a tangential and radial full width at half maximum of $1.5 \mathrm{~mm}$ at the center of the field of view and $1.8 \mathrm{~mm}$ at the edge of the field of view. PET and CT images were coregistered with Inveon Research Workstation (IRW) software (Siemens Medical Solutions). PET 
images were reconstructed and analyzed using IRW. Regions of interest were drawn using the CT scan, and the associated PET activities were calculated using the IRW software.
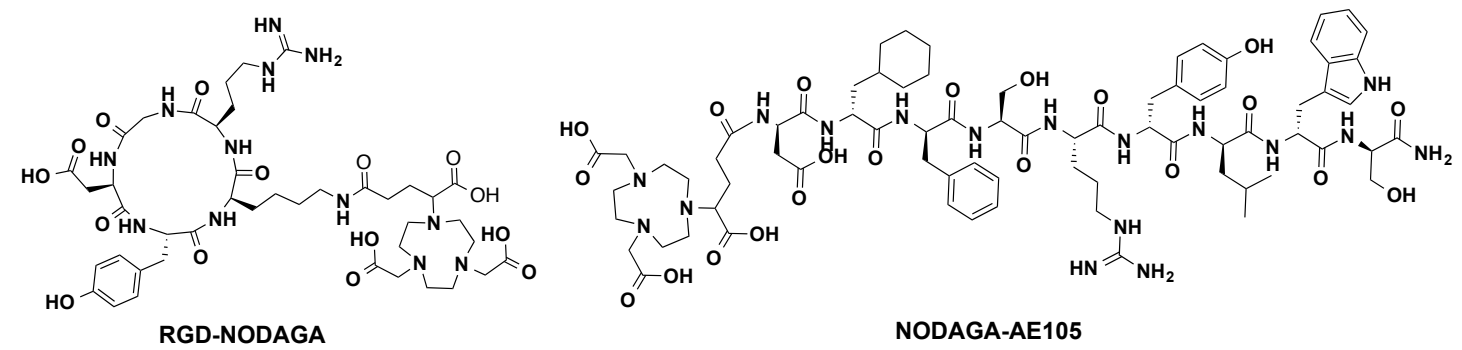

NODAGA-AE105

\section{References:}

1. Gai Y, Hu Z, Rong Z, et al. Molecules, 2015, 20(10): 19393-19405.

2. Goddard-Borger, E. D., \& Stick, R. V., Org Lett 2007, 9, 3797-3800.

3. Frisch, M. J.; Gaussian 09, revision C. 01; Gaussian, Inc.: Wallingford, CT, 2010.

4. (a) Becke, A. D. J. Chem. Phys. 1993, 98, 5648-5652. (b) Lee, C.; Yang, W.; Parr, R. G. Phys. Rev. B 1988, 37 , 785-789.

5. (a) Barone, V.; Cossi, M. J. Phys. Chem. A 1998, 102, 1995-2001. (b) Cossi, M.; Rega, N.; Scalmani, G.; Barone, V. J. Comput. Chem. 2003, 24, 669-681.

6. Liu S, Liu H, Jiang H, et al., Eur. J. Nucl. Med. Mol. Imaging 2011, 38, 1732-1741.

7. Boswell C A, Sun X, Niu W, et al. J. Med. Chem. 2004, 47(6): 1465-1474. 